\title{
əMixing and Transformation in a Deep Western Boundary Current: A Case Study
}

\author{
Carl P. Spingys, ${ }^{a}$ Alberto C. Naveira Garabato, ${ }^{a}$ Sonya LegG,${ }^{b}$ Kurt L. Polzin, ${ }^{c}$ E. Povl Abrahamsen, ${ }^{d}$ \\ Christian E. Buckingham, ${ }^{\mathrm{e}}$ AleXANDER Forryan, ${ }^{\mathrm{a}}$ AND ElEANOr E. FrajKA-Williams ${ }^{\mathrm{f}}$ \\ ${ }^{a}$ Ocean and Earth Science, National Oceanography Centre, University of Southampton, Southampton, United Kingdom \\ ${ }^{\mathrm{b}}$ Atmospheric and Oceanic Sciences Program, Princeton University, Princeton, New Jersey \\ ${ }^{\mathrm{c}}$ Department of Physical Oceanography, Woods Hole Oceanographic Institution, Woods Hole, Massachusetts \\ ${ }^{\mathrm{d}}$ British Antarctic Survey, Cambridge, United Kingdom \\ ${ }^{\mathrm{e}}$ Laboratoire d'Oceanographie Physique et Spatiale, CNRS, IRD, Ifremer, UBO, Plouzané, France \\ ${ }^{\mathrm{f}}$ National Oceanography Centre, Southampton, United Kingdom
}

(Manuscript received 23 June 2020, in final form 4 January 2021)

\begin{abstract}
Water-mass transformation by turbulent mixing is a key part of the deep-ocean overturning, as it drives the upwelling of dense waters formed at high latitudes. Here, we quantify this transformation and its underpinning processes in a small Southern Ocean basin: the Orkney Deep. Observations reveal a focusing of the transport in density space as a deep western boundary current (DWBC) flows through the region, associated with lightening and densification of the current's denser and lighter layers, respectively. These transformations are driven by vigorous turbulent mixing. Comparing this transformation with measurements of the rate of turbulent kinetic energy dissipation indicates that, within the DWBC, turbulence operates with a high mixing efficiency, characterized by a dissipation ratio of 0.6 to 1 that exceeds the common value of 0.2 . This result is corroborated by estimates of the dissipation ratio from microstructure observations. The causes of the transformation are unraveled through a decomposition into contributions dependent on the gradients in density space of the: dianeutral mixing rate, isoneutral area, and stratification. The transformation is found to be primarily driven by strong turbulence acting on an abrupt transition from the weakly stratified bottom boundary layer to well-stratified off-boundary waters. The reduced boundary layer stratification is generated by a downslope Ekman flow associated with the DWBC's flow along sloping topography, and is further regulated by submesoscale instabilities acting to restratify near-boundary waters. Our results provide observational evidence endorsing the importance of near-boundary mixing processes to deep-ocean overturning, and highlight the role of DWBCs as hot spots of dianeutral upwelling.
\end{abstract}

KEYWORDS: Bottom currents; Diapycnal mixing; Turbulence; Southern Ocean; Abyssal circulation

\section{Introduction}

The deep ocean exerts a pivotal control on Earth's climate by storing large quantities of heat, carbon and other climatically important tracers for centuries to millennia (Watson and Naveira Garabato 2006; Purkey and Johnson 2013; Ferrari et al. 2014; Desbruyeres et al. 2016), as well as influencing the rate and structure of the circulation in the ocean's upper layers (Patara and Boning 2014). Since the seminal works of Stommel and Arons (1960) and Munk (1966) (see also Nikurashin and Vallis 2011, 2012), it has been recognized that the deep ocean's climatic role is defined by its stratification and overturning circulation, and that these are established by a balance between (i) the sinking of dense waters formed in areas of the North Atlantic and Southern Oceans, and (ii) the upwelling and lightening of those waters by turbulent diapycnal mixing. These two ingredients of deep-ocean stratification and overturning, however, have different spatial footprints, whose connectivity is poorly characterized and understood. Specifically, the dense waters are primarily spread from their high-latitude formation

¿ Denotes content that is immediately available upon publication as open access.

Corresponding author: Carl P. Spingys, c.p.spingys@soton.ac.uk sites via deep western boundary currents (DWBCs) (Stommel and Arons 1960; Kawase 1987; Talley 2013), while diapycnal mixing is focused over more extensive areas of rough and steep seafloor topography (Polzin et al. 1997; Waterhouse et al. 2014; de Lavergne et al. 2016b). Developing a complete picture of the deep-ocean circulation thus calls for an assessment of the pathways linking DWBCs with hotspots of diapycnal upwelling.

A step toward the resolution of this problem is suggested by a range of studies (Thompson and Johnson 1996; Huussen et al. 2012; de Lavergne et al. 2016b; Ferrari et al. 2016; McDougall and Ferrari 2017; Callies 2018; Naveira Garabato et al. 2019; Cimoli et al. 2019) that highlight turbulent mixing in bottom boundary layers as a key, possibly dominant, mechanism driving the lightening of dense waters sourced at high latitudes. This view is distinct from the prevalence of internal wave-driven mixing in the ocean interior in driving diapycnal upwelling (Huussen et al. 2012; Kunze 2017), which had been assumed by several decades of previous investigations, and raises the prospect that a substantial fraction of the basin-scale upwelling may occur within DWBCs. Such a possibility is qualitatively endorsed by direct (Naveira Garabato et al. 2019) and indirect

This article is licensed under a Creative Commons Attribution 4.0 license (http://creativecommons.org/ licenses/by/4.0/).

DOI: 10.1175/JPO-D-20-0132.1 


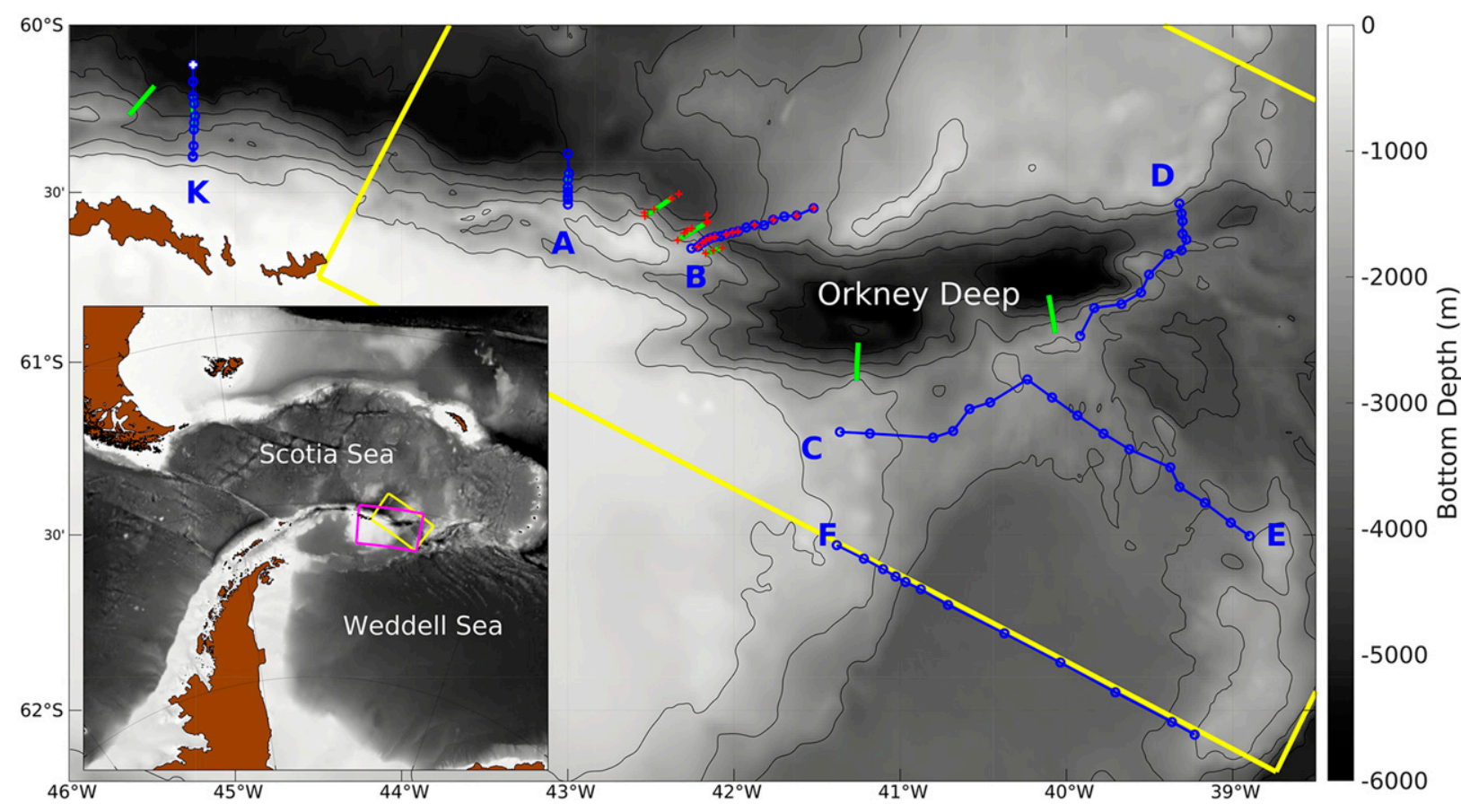

FIG. 1. Location of the data used in this study. The magenta box in the inset map is the region where observations were made, and the boundaries of the larger map. The yellow boxes on both the inset and main figure show the domain simulated by the numerical model. The blue lines represent the sections across the Orkney Passage, with the circles indicating the locations of the CTD/LADCP profiles. The green lines show the positions of the high-horizontal-resolution tow-yo sections. The red crosses mark the positions of the VMP microstructure profiles used in this study. The white cross at the end of section K marks the position of the CTD profile, 119, used to set the initial stratification in the model.

(Stöber et al. 2008; Kunze 2017) observational estimates of turbulent mixing in DWBCs, which reveal the presence of large mixing rates. In this paper, we will quantitatively test the hypothesis that near-boundary mixing associated with a DWBC is the main driver of diapycnal upwelling in a small deep-ocean basin, and will elucidate the processes underpinning this upwelling.

The deep-ocean basin chosen for our case study is the Orkney Deep (Fig. 1), a $150 \mathrm{~km} \times 50 \mathrm{~km}, 6325$-m-deep bowl-shaped basin within the Orkney Passage complex, at the boundary between the Weddell and Scotia Seas in the Southern Ocean. The Orkney Deep possesses three features that make it particularly well suited for our test. First, it has a small area and pronounced topographic boundaries, being surrounded by a shallow (500-1800 $\mathrm{m}$ deep) plateau to the north, the continental shelf of the Orkney Islands to the south, and 3400- and 3650-m sills to the east and west, respectively. This geometry enables the deep water-mass budget and mixing environment for the basin to be characterized with a number of oceanographic measurements attainable in a single research cruise. Second, the Orkney Deep is traversed by a strong, topographically steered DWBC, which represents one of the major outflows of Antarctic Bottom Water (AABW) from the polar Southern Ocean (Gordon et al. 2001; Naveira Garabato et al. 2002, 2014) and whose association with intense turbulent mixing has been documented (Heywood et al. 2002; Polzin et al. 2014; Naveira Garabato et al. 2019). And third, the basin hosts a multiannual mooring array measuring the DWBC transport (Abrahamsen et al. 2019), which may be used to appraise the representativeness of ship-based "snapshot" observations.
The paper is structured as follows. In section 2, we introduce the observations and numerical simulation considered in this study. Section 3 describes the deep circulation within the Orkney Passage, providing the context for subsequent analyses. In section 4, we present a volume budget for density layers that will serve to quantify dianeutral transports. In section 5, the water-mass transformation framework for dianeutral transports is introduced, with initial estimates for individual processes. Dianeutral transports are then estimated from the convergence of observed lateral transports in section 6 , and the implications for turbulent mixing-driven dianeutral transformations are discussed in section 7. In section 8 , we decompose the dianeutral transformations into distinct contributions, and characterize the role of bottom boundary processes in driving such transformations. Finally, our conclusions are summarized, and their potential global implications considered, in section 9.

\section{Methods}

Our investigation of dianeutral transports and turbulent mixing-driven dianeutral transformations in the Orkney Deep is based on a range of datasets, both observational and from numerical modeling.

\section{a. Observations}

\section{1) CTD/LADCP SECTIONS}

In March-April 2017, an intensive observational campaign was performed on the RRS James Clark Ross to survey the 
hydrography, velocity, and shear and temperature microstructure of the DWBC flowing through the Orkney Passage. This work was performed as part of the Dynamics of the Orkney Passage Outflow (DynOPO) and Ocean Regulation of Climate by Heat and Carbon Sequestration and Transports (ORCHESTRA) projects. The DWBC was measured with 15 sections at different locations in the Passage. These sections took two forms: seven full-depth transects across the width of the Passage, at a horizontal resolution of $2-10 \mathrm{~km}$ (blue lines in Fig. 1) and eight "tow-yo" transects across the DWBC's onshore edge, focused on depths greater than $1000 \mathrm{~m}$ with an approximate horizontal resolution of $350 \mathrm{~m}$ (green lines in Fig. 1). All sections consisted of CTD hydrographic and lowered acoustic Doppler current profiler (LADCP) horizontal velocity stations. CTD conductivity data were calibrated using discrete bottle samples, and LADCP data were processed using the inverse method implemented in the Lamont-Doherty Earth Observatory routines (Visbeck 2002; Naveira Garabato 2017). LADCP velocities are subject to substantial uncertainty, which consists of an instrument-derived error applying primarily to the depth-varying component of the measured flow, and an error associated with the estimation of the depth-mean component. Uncertainty in the depth-varying component is typically small, on the order of $0.5 \mathrm{~cm} \mathrm{~s}^{-1}$, compared to the flows expected here. In turn, uncertainty in the depth-mean component can be larger. This depth-mean error is estimated here by comparing LADCP velocities in the deepest part of each profile to semi-independent velocities from the LADCP's bottom tracking (Naveira Garabato et al. 2002). This yields maximum depth-mean errors of $1.1-2.8 \mathrm{~cm} \mathrm{~s}^{-1}$, which amount to $5 \%-10 \%$ of the DWBC's flow (Naveira Garabato et al. 2019).

\section{2) Microstructure dAtA}

Along the same transects as the CTD/LADCP sections, profiles of turbulent microstructure were acquired with a Rockland Scientific International (RSI) Vertical Microstructure Profiler 6000. These profiles spanned nearly the full water column, ending approximately $50 \mathrm{~m}$ from the seabed. A limited number of profiles sampled within the bottom $50 \mathrm{~m}$, providing information on turbulent parameters very close to the seabed. The rates of dissipation of turbulent kinetic energy (TKE) and of temperature variance were calculated using standard methods from Oakey (1982) (see Naveira Garabato et al. 2019). A correction for the attenuated high-frequency, greater than $15 \mathrm{~Hz}$, portions of the temperature spectra was applied, using the Kraichnan spectrum (Bogucki et al. 2012).

\section{3) Autosub LONG RANGe}

In addition to vertical profiles collected from the ship, a horizontal mapping of the properties of the DWBC was conducted using the autonomous underwater vehicle Autosub Long Range (ALR) (Furlong et al. 2012). ALR was programmed to perform a radiator, isobar-following survey consisting of 17-20-km-long legs separated by $250 \mathrm{~m}$ in water depth. The total track length of the ALR mission considered here was $178 \mathrm{~km}$ over $75 \mathrm{~h}$, with a height-above-bottom ranging from 60 to $140 \mathrm{~m}$, averaging to $90 \mathrm{~m}$. The vehicle was equipped with a Sea-Bird Scientific SBE-52MP CTD, upward- and downward-looking 300-kHz ADCPs, and an RSI Microrider microstructure probe. This gives the same suite of hydrographic, velocity and microstructure variables as collected in the CTD/LADCP/VMP sections, but with improved horizontal sampling of the near-bottom flow and turbulence. See Naveira Garabato et al. (2019) for a detailed account of ALR data processing.

\section{4) MOORINGS}

The Orkney Passage mooring array consists of six oceanographic moorings running across the saddle point of the Passage from approximately $1750-\mathrm{m}$ depth in the west, past the deepest point, to 2310-m depth in the east. Five of these moorings have been deployed since 2011, with the sixth first deployed in 2012. Instrumentation includes single-point current meters, temperature, temperature-pressure, and conductivity-temperaturepressure recorders. The array was designed to capture the variability of AABW export from the Weddell Sea. While the array always covers the extent of the Lower Weddell Sea Deep Water $\left(28.31<\gamma<28.4 \mathrm{~kg} \mathrm{~m}^{-3}\right)$ class of AABW, the lighter AABW range $\left(28.26<\gamma<28.31 \mathrm{~kg} \mathrm{~m}^{-3}\right)$ occasionally extends to shallower depths than the top of the moorings.

To calculate volume fluxes through the moorings, velocities are rotated along the main axis of the mooring array. Daily averages are calculated both for this velocity, and for temperatures, salinities and pressures of each instrument. In cases where pressure is not measured, it is interpolated from surrounding instruments, based on the deployment depths of the instruments. For each instrument that does not measure conductivity but does measure temperature, a salinity is calculated as a linear function of temperature, using the two nearest instruments with salinity data, if these are both within $150 \mathrm{~m}$ of the instrument. If this is not possible, they are calculated using all measured temperature and salinity data from the pertinent deployment.

For each day, the rotated current speed, temperature, and salinity are interpolated bilinearly onto a regular grid at an approximate resolution of $345 \mathrm{~m}$ horizontally and $8 \mathrm{~m}$ vertically. A low-pass filter (fifth-order Chebyshev Type I with 400-m cutoff wavelength) is then applied to the data in the vertical. Any data interpolated farther than the distance between two adjacent moorings are removed, and data are extended to the seabed (using the dataset of Abrahamsen 2019), by repeating the deepest data point. Neutral densities are then calculated using the code from Jackett and McDougall (1997). For those positions where the shallowest measurements are less dense than $\gamma=28.26 \mathrm{~kg} \mathrm{~m}^{-3}$, the density profiles are extrapolated upward up to this value based on neutral density gradients from CTD casts. The shallowest current measurements are repeated to bring them up to this level.

\section{b. Model}

The DWBC flow through the Orkney Passage is also investigated using a Massachusetts Institute of Technology General Circulation Model (MITgcm) (Marshall et al. 1997) simulation (Naveira Garabato et al. 2019). This model simulation will be used to provide information on the DWBC's density structure in areas away from the observations. The model is run with a time 

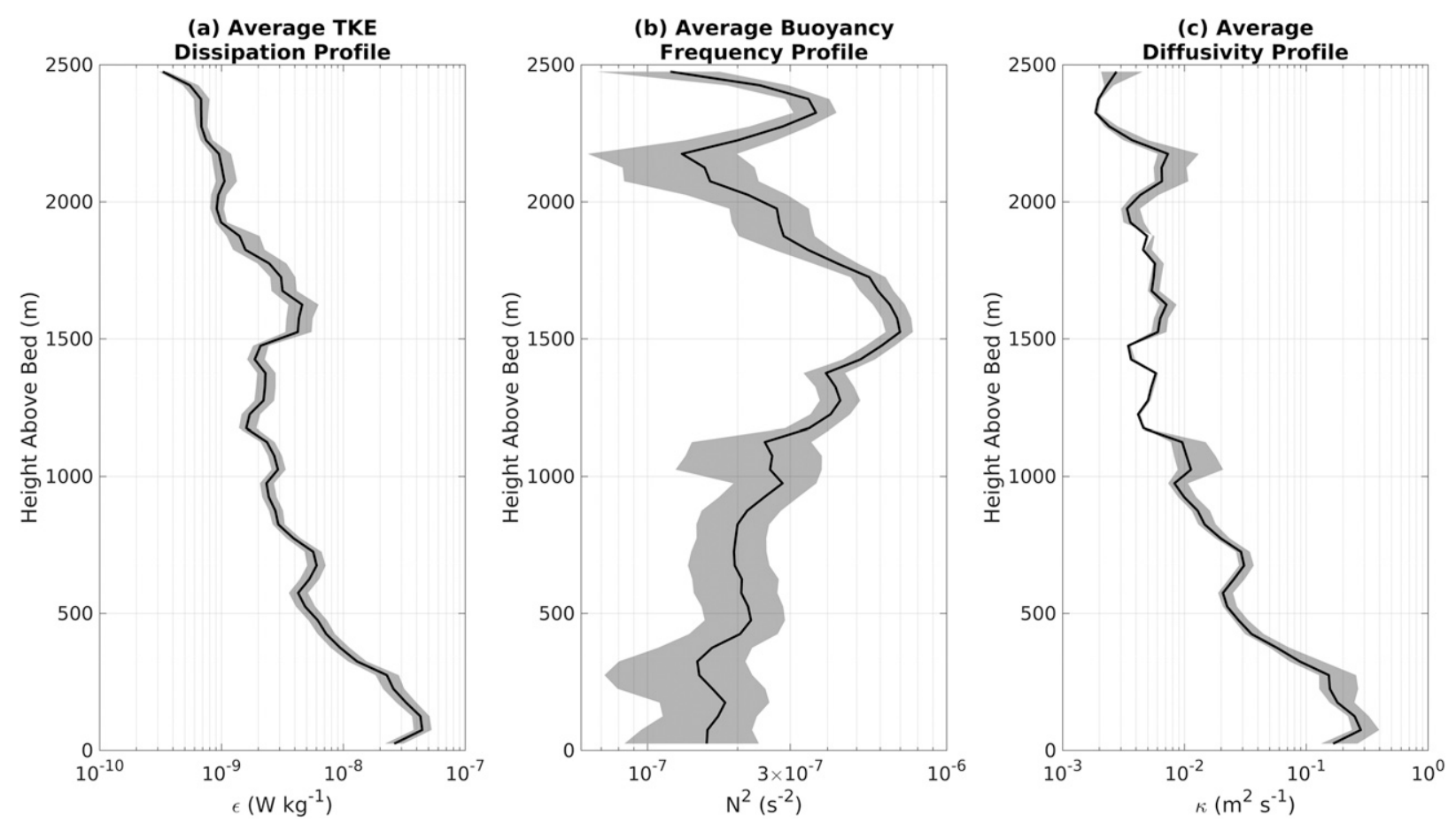

FIG. 2. The average profile in height-above-bed coordinates of (a) turbulent kinetic energy dissipation rate, (b) buoyancy frequency, and (c) dianeutral diffusivity, derived from observational microstructure data.

step of $50 \mathrm{~s}$, a horizontal resolution of $1 \mathrm{~km}$, and a vertical resolution of $63.3 \mathrm{~m}$. The simulation is initialized with a horizontally uniform temperature and salinity taken from the CTD profile at station 119 in the deep Scotia Sea, and zero flow. The southern boundary is forced with the observed flow and hydrography at section F (Fig. 1). The remaining boundaries are open, with a net outflow matching the inflow at the southern boundary, and with temperature and salinity relaxed to the initial profile. The model does not have surface or tidal forcing. The model has a single imposed vertical diffusivity profile throughout the domain, calculated from observations of TKE dissipation rate and buoyancy frequency averaged in height-above-seabed bins (Fig. 2c) and a dissipation ratio of 0.8 , consistent with the results presented in section 5d. A second-order flux-limited advection scheme is used. A comparison was made with a simulation run with the Prather scheme with a flux limiter (Prather 1986), and there were no significant differences in the results. The model is run for 2.6 years, until it reached a statistically steady state, determined on the basis of the average temperature below $3800 \mathrm{~m}$ within Orkney Deep. The density and velocity fields used in our analysis are taken from the end of the run.

\section{Circulation in the Orkney Passage}

The deep circulation within the Orkney Passage is dominated by the DWBC flowing from the Weddell Sea to the Scotia Sea. This flow approximately follows the 3000-m isobath, with shoaling topography to the left. Upstream of the Orkney Deep, where the topographic slope is gentle, the DWBC has a width of $30 \mathrm{~km}$ and velocities of $\sim 0.1 \mathrm{~m} \mathrm{~s}^{-1}$ (Fig. 3). After Orkney Deep, where the topography has become much steeper, the DWBC is more intense, $>0.2 \mathrm{~m} \mathrm{~s}^{-1}$, but narrower, $15 \mathrm{~km}$ (Fig. 3). There is some return flow on the opposite side of Orkney Deep, possibly indicating partial recirculation of the $\mathrm{DWBC}$, but the flow is weaker than in the northward-flowing DWBC, leading to a net transport toward the Scotia Sea through every section.

The total AABW transport through the Orkney Passage varies between the sections, from $3.49 \mathrm{~Sv}\left(1 \mathrm{~Sv} \equiv 10^{6} \mathrm{~m}^{3} \mathrm{~s}^{-1}\right)$ at the combined section $\mathrm{C}+\mathrm{E}$ to $1.89 \mathrm{~Sv}$ at section $\mathrm{B}$ (Table 1 ). This inconsistency between the sections could have a range of explanations: aliasing of high-frequency temporal variability by sampling different sectors of the DWBC at different times; a trend in the volume of $\mathrm{AABW}$ within Orkney Deep; substantial flow across the unsampled shallow regions bounding Orkney Deep; or the CTD/LADCP station positions not capturing parts of the flow. Examining these possibilities reveals the following:

- The moorings, located at section B, endorse the first explanation by revealing significant temporal variability in the strength of the DWBC (Abrahamsen et al. 2019), which has a decorrelation time scale (autocorrelation $R=0.2$ for a 10-day lag) that is comparable to a time scale for transport through Orkney Deep (11.5 days for a flow of $0.15 \mathrm{~m} \mathrm{~s}^{-1}$ to travel $150 \mathrm{~km}$ ). This indicates that the apparent spatial variability in AABW transports between sections A to F may plausibly be aliased highfrequency temporal variability. For section $\mathrm{K}$, the observed transport is noticeably larger, $4.84 \mathrm{~Sv}$, likely as a result of recirculation within the Scotia Sea (Gordon et al. 2001).

- A volume tendency can be estimated in neutral density bins by taking the cross-sectional areas of those bins, from the moorings at section $\mathrm{B}$, and extending the cross-sectional 
(a) Section D - Observed Density and Stratification

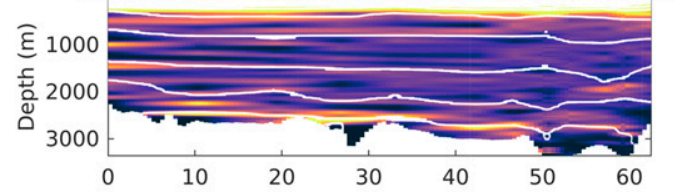

(c) Section D - Model Density and Stratification

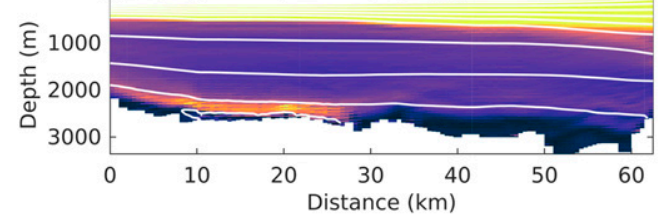

(b) Section D - Observed Velocity

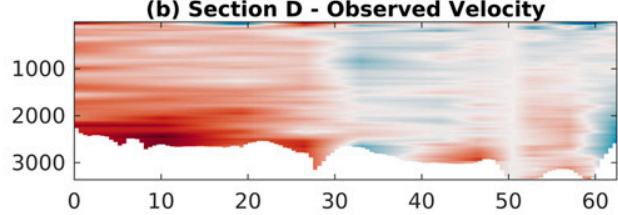

(d) Section D - Model Velocity

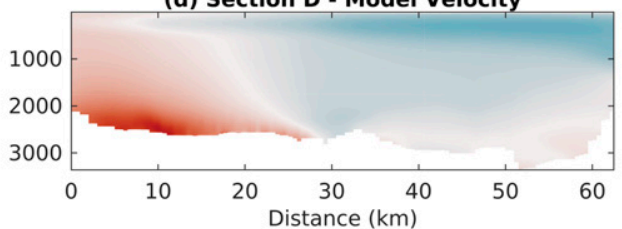

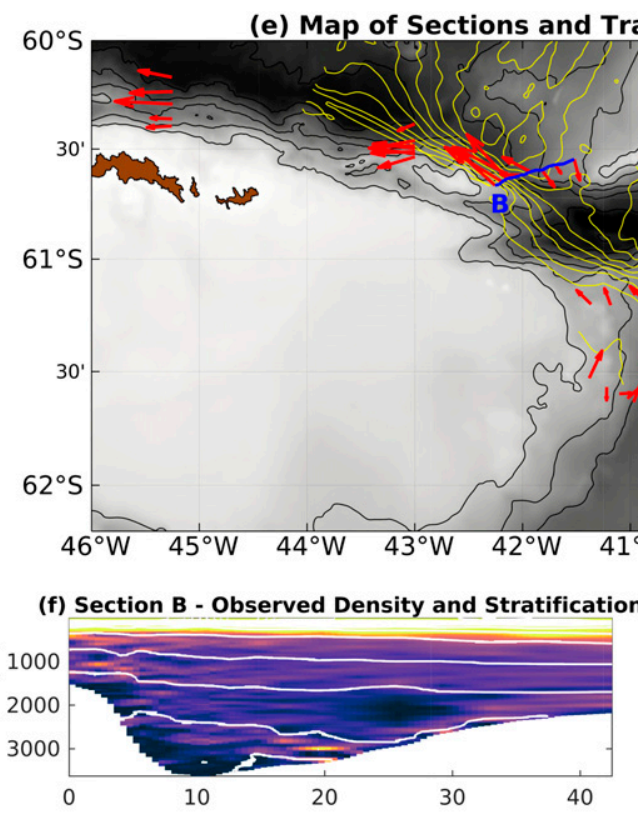

(h) Section B - Model Density and Stratification

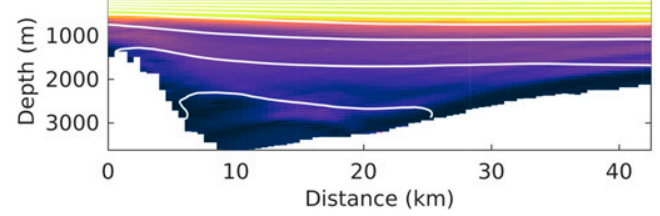

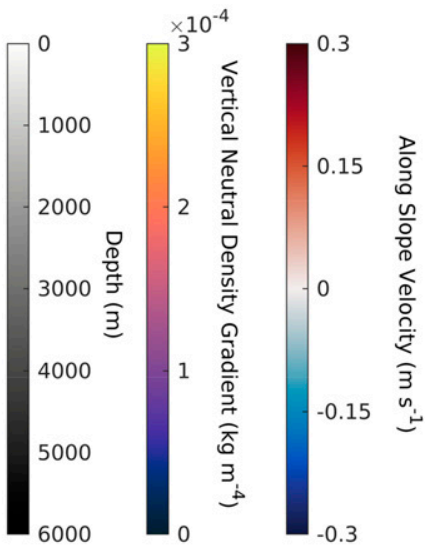

(g) Section B - Observed Velocity

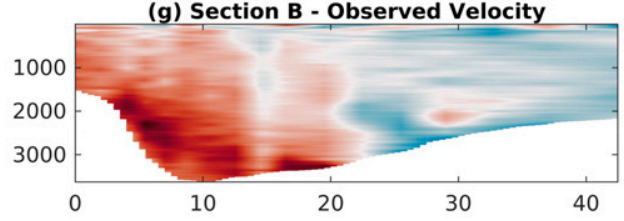

(i) Section B - Model Velocity

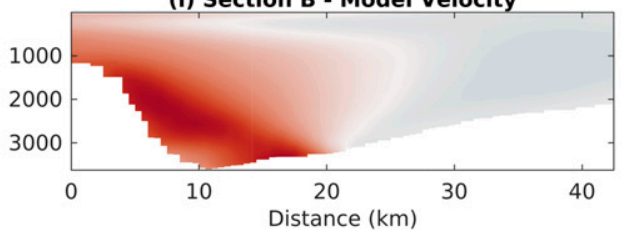

FIG. 3. The evolution of the DWBC in the Orkney Passage from (a),(b),(f),(g) observations and(c),(d),(h),(i) the numerical model. Sections of neutral density stratification (background colors) and surfaces (white lines) in (a), (c), (f), and (h) and along-slope velocity in (b), (d), (g), and (i) are presented from both the observations and model for two crossings of the Passage, one upstream of the Orkney Deep (section D) and the other downstream of the Orkney Deep (section B). (e) The map shows the deep circulation of the Orkney Passage, with red arrows showing the average velocity of water denser than $28.26 \mathrm{~kg} \mathrm{~m}^{-3}$ from observations and yellow lines indicating contours of the depth-integrated streamfunction in the model of water denser than $28.26 \mathrm{~kg} \mathrm{~m}^{-3}$.

areas through the $150 \mathrm{~km}$ of Orkney Deep. Applying this approach to densities greater than $28.26 \mathrm{~kg} \mathrm{~m}^{-3}$ gives a volume tendency of $0.18 \mathrm{~Sv}$ within that density class, suggesting that a trend in the volume of AABW within Orkney Deep cannot account for measured transport differences between sections. Unfortunately, we cannot evaluate the accuracy of the assumed cross-sectional areas in this calculation due to a lack of observations in the interior of Orkney Deep.
However, the result reported here is endorsed by a recent analysis of repeat sections downstream of Orkney Deep (Abrahamsen et al. 2019).

- The numerical model indicates that the transport across the side boundaries of the Orkney Deep, not captured by our sections, is at most $8 \%$ of the transport through the sections. This indicates that our sections adequately measure the flow through the Orkney Passage. 
TABLE 1. Total transport of volume denser than $28.26 \mathrm{~kg} \mathrm{~m}^{-3}$ through each of the CTD/LADCP sections, alongside the dates at which each section was occupied (in 2017).

\begin{tabular}{ccc}
\hline \hline Section & Transport (Sv) & Dates of observations \\
\hline A & 2.53 & $24-26 \mathrm{Apr}$ \\
B & 1.89 & $10-18 \mathrm{Apr}$ \\
C & 0.57 & $31 \mathrm{Mar}$ \\
D & 2.60 & $2-6 \mathrm{Apr}$ \\
E & 2.92 & $29-30 \mathrm{Mar}$ \\
F & 2.24 & $24-27 \mathrm{Mar}$ \\
K & 4.84 & $27-30 \mathrm{Apr}$ \\
\hline
\end{tabular}

Superimposed on these mesoscale flows of deep waters within the Orkney Passage, the DWBC exhibits a series of smaller-scale motions in the vicinity of the sloping boundary. These motions include: a downslope-directed bottom Ekman flow, inducing weak stratification in the bottom $200-300 \mathrm{~m}$ (Naveira Garabato et al. 2019); a "swash layer" with pronounced temporal variability over the deepest several hundred meters (K. Polzin et al. 2021, unpublished manuscript); and topographic eddies, likely generated by submesoscale instabilities (Naveira Garabato et al. 2019).

The deep circulation simulated by the model agrees well with observations (Fig. 3e). The model reproduces both the structure and magnitude of the velocities measured in the sections (Fig. 3b versus Fig. 3d, and Fig. 3g versus Fig. 3i). The stratification at section $\mathrm{D}$ is also in good agreement with observations, although it is a little weaker than measured. Some of the densest water observed is missing near the north of the model domain (Fig. 3a versus Fig. 3c). A similar pattern is seen in section $B$, where the model realistically represents the observed density structure but with a small bias toward weak stratification and light density in the densest layers (Fig. $3 f$ versus Fig. 3h). This bias is likely a consequence of imposing a single mixing profile throughout the model domain.

\section{Relating dianeutral transport to a volume budget}

Water-mass budgets are a commonly used tool to describe the transformations between different water types in the global ocean circulation (Walin 1982; Nurser et al. 1999; Iudicone et al. 2008; de Lavergne et al. 2016b; Groeskamp et al. 2019). Here, we recall some of the aspects of these budgets that will be applied in the following sections, primarily following Nurser et al. (1999) and Iudicone et al. (2008).

We begin by considering a regional budget for the volume between two isoneutrals, the ocean surface, and topography:

$$
\frac{\partial V}{\partial t}=M+\Psi_{P-E}+\Delta \Psi_{\text {lat }}
$$

where $\partial V / \partial t$ is the rate of change of volume, which can be driven by a combination of the formation or destruction of water within the region, $M$; the addition or removal of volume by surface precipitation and evaporation, $\Psi_{P-E}$; and the convergence of volume transport through the lateral boundaries of the region, $\Psi_{\text {lat }}$ (Fig. 4a). (a) Volume budget

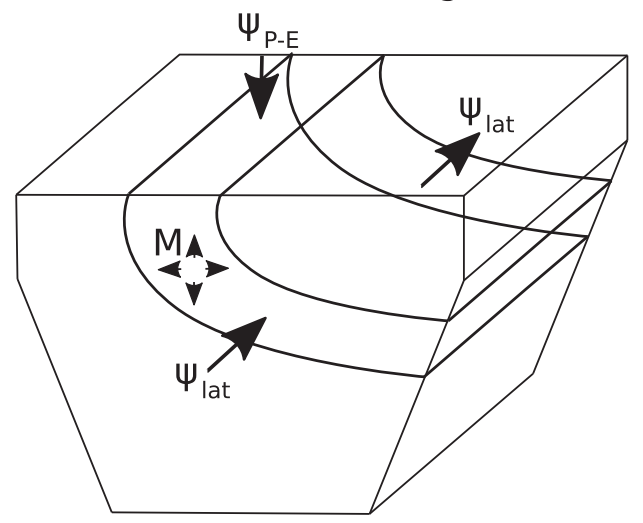

(b) Transformation budget

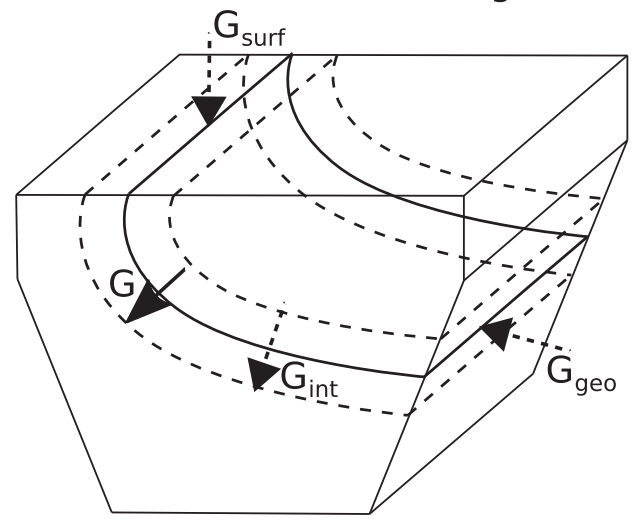

FIG. 4. Schematics of the different contributions to (a) the volume budget and (b) the water-mass transformation budget.

In this study, we investigate water-mass transformations within a DWBC. As a result, we exclude the term driven by surface volume flux $\Psi_{P-E}$, as the relevant isoneutrals do not outcrop. If we further assume that the density field is in steady state within the domain, $\partial V / \partial t=0$, then we are left with a balance between the convergence of the lateral transport $\Delta \Psi_{\text {lat }}$ and the formation rate $M$. The steady-state assumption is supported by the cross-sectional area of neutral density bins exhibiting a root-mean-square volume tendency that is $<1 \%$ of the observed convergence, and a maximum of $20 \%$ of the convergence, at the moorings in section B. However, observations to evaluate this tendency throughout Orkney Deep do not exist.

The formation rate $M$ can be regarded as the convergence of volume transport across the isoneutral boundaries of the volume considered,

$$
M=-\frac{\partial G}{\partial \gamma},
$$

where $G$ is the volume flux across an isoneutral, with a positive flux directed toward denser water, and $\gamma$ is the neutral density.

\section{Water-mass transformation framework}

By considering a density budget next, the dianeutral transport $G$ can be related to water-mass transformations, and linked to 
the physical processes that modify the density (Nurser et al. 1999). The dianeutral transport may then be decomposed into the contributing transformation processes,

$$
G=G_{\text {surf }}+G_{\text {int }}+G_{\text {geo }},
$$

with contributions from surface buoyancy forcing $G_{\text {surf }}$, which is zero for our deep-ocean case; internal processes $G_{\text {int }}$, including dianeutral mixing and effects of a nonlinear equation of state; and geothermal heating $G_{\text {geo }}$ (Fig. 4b). We will next explore the latter two contributions, in order to identify the leading-order term(s) in our DWBC problem.

\section{a. Internal transformation}

The internal transformation $G_{\text {int }}$ can be expressed as the isoneutral integral of the dianeutral velocity $w_{*}$, defined as positive when directed toward denser water,

$$
G_{\text {int }}=\iint_{\gamma} w_{*} \partial A .
$$

This dianeutral velocity can then be written as

$$
w_{*}=w_{\text {mix }}+w_{\text {cab }}+w_{\text {therm }},
$$

where $w_{\text {mix }}$ is the velocity driven by dianeutral mixing, and $w_{\text {cab }}$ and $w_{\text {therm }}$ are induced by nonlinearities in the equation of state (cabbeling and thermobaricity, respectively) (McDougall 1984).

\section{1) Dianeutral MiXing}

The dianeutral velocity driven by mixing of neutral density gradients is given by

$$
w_{\text {mix }}=\frac{\partial}{\partial \gamma}\left(-\kappa_{\perp} \frac{\partial \gamma}{\partial z}\right),
$$

where $\kappa_{\perp}$ is the dianeutral diffusivity. This can be expressed as a function of the buoyancy flux $B_{f}$,

$$
w_{\text {mix }}=\frac{\partial}{\partial \gamma}\left(\frac{B_{f} \rho_{0} b}{g}\right),
$$

where $b$ is the ratio of the vertical gradients of neutral and potential density.

This bypasses the need to know the vertical gradient of neutral density within the domain to evaluate the turbulent mixing implied by a water-mass budget. The buoyancy flux is often considered to be proportional to the rate of dissipation of TKE by viscosity, $\epsilon$, i.e.,

$$
B_{f}=\Gamma \epsilon,
$$

where $\Gamma$ is the ratio of the buoyancy flux to the turbulent dissipation (Osborn 1980). This ratio will be termed "dissipation ratio" in this study, but is often referred to as "mixing efficiency." The dissipation ratio has often been assumed to adopt a constant value of 0.2 in previous studies (Gregg et al. 2018). If we take typical values for the inputs $\left(\Gamma=0.2, \rho_{0}=\right.$ $1025 \mathrm{~kg} \mathrm{~m}^{-3}, b=2$ (see section $\left.7 \mathrm{~b}\right), g=9.81 \mathrm{~m} \mathrm{~s}^{-2}$ ) and the range of the observed TKE dissipation rate over the deepest
$1000 \mathrm{~m}$ (from $\epsilon=2 \times 10^{-9}$ to $4.5 \times 10^{-8} \mathrm{~W} \mathrm{~kg}^{-1}$ over a density range of $\partial \gamma=3.5 \times 10^{-2} \mathrm{~kg} \mathrm{~m}^{-3}$ ), then the implied dianeutral velocity is $w_{\text {mix }}=5.1 \times 10^{-5} \mathrm{~m} \mathrm{~s}^{-1}$. This equates to a transformation of $G_{\text {mix }}=2.1 \times 10^{-1} \mathrm{~Sv}$, using an isoneutral area of $A=4 \times 10^{9} \mathrm{~m}^{2}$.

\section{2) EFFECTS OF THE NONLINEAR EQUATION OF STATE}

There is also a dianeutral velocity driven by nonlinearities in the equation of state. This can be split into two components, cabbeling and thermobaricity (Klocker and McDougall 2010). The cabbeling-driven dianeutral velocity is given by

$$
\begin{gathered}
w_{\mathrm{cab}}=\frac{b g}{N^{2}} \kappa_{\|} C_{b}\left(\nabla_{\gamma} \theta \cdot \nabla_{\gamma} \theta\right), \\
C_{b}=\frac{\partial \alpha}{\partial \theta}+2 \frac{\alpha}{\beta} \frac{\partial \alpha}{\partial S}-\frac{\alpha^{2}}{\beta^{2}} \frac{\partial \beta}{\partial S},
\end{gathered}
$$

with $\alpha$ as the thermal expansion coefficient and $\beta$ as the haline contraction coefficient.

The thermobaricity-driven dianeutral velocity is given by

$$
\begin{aligned}
w_{\text {therm }} & =\frac{b g}{N^{2}} \kappa_{\|} T_{b}\left(\nabla_{\gamma} \theta \cdot \nabla_{\gamma} p\right), \\
T_{b} & =\frac{\partial \alpha}{\partial p}-\frac{\alpha}{\beta} \frac{\partial \beta}{\partial p} .
\end{aligned}
$$

Taking typical values for the inputs $\left(b=2, g=9.81 \mathrm{~m} \mathrm{~s}^{-2}, N^{2}=\right.$ $3 \times 10^{-7} \mathrm{~s}^{-2}, \kappa_{\|}=5 \times 10^{2} \mathrm{~m}^{2} \mathrm{~s}^{-1}, C_{b}=1.1 \times 10^{-5}{ }^{\circ} \mathrm{C}^{-2}, T_{b}=$ $2.7 \times 10^{-8}{ }^{\circ} \mathrm{C}^{-1} \mathrm{dbar}^{-1}$ ) and cross-flow isoneutral gradients from the section measurements $\left(\nabla_{\gamma} \theta=-1.2 \times 10^{-6}{ }^{\circ} \mathrm{Cm}^{-1}, \nabla_{\gamma} p=\right.$ $6.1 \times 10^{-3} \mathrm{dbar} \mathrm{m}^{-1}$ ) gives a cabbeling-induced dianeutral velocity of $w_{\text {cab }}=5.18 \times 10^{-7} \mathrm{~m} \mathrm{~s}^{-1}$ and a thermobaricity-induced dianeutral velocity of $w_{\text {therm }}=-6.5 \times 10^{-6} \mathrm{~m} \mathrm{~s}^{-1}$. These velocities, when applied to an isoneutral area of $A=4 \times 10^{9} \mathrm{~m}^{2}$, result in transformations of $G_{\mathrm{cab}}=2.1 \times 10^{-3} \mathrm{~Sv}$ due to cabbeling and $G_{\text {therm }}=-2.6 \times 10^{-2} \mathrm{~Sv}$ due to thermobaricity.

\section{b. Geothermal heating}

Transformation is also driven by geothermal forcing at the bottom boundary. This transformation, $G_{\text {geo }}$, is given by the heating integrated over the incrop area (de Lavergne et al. 2016b),

$$
G_{\mathrm{geo}}=-\frac{1}{\Delta \gamma} \iint_{\text {incrop }} \frac{b \alpha Q_{\mathrm{geo}}}{c_{p}} d A,
$$

where $Q_{\text {geo }}$ is the geothermal heat flux.

Using representative values for the inputs $(\Delta \gamma=2 \times$ $10^{-2} \mathrm{~kg} \mathrm{~m}^{-3}, A_{\text {incrop }}=4 \times 10^{9} \mathrm{~m}^{2}, b=2, \alpha=1.2 \times 10^{-4}{ }^{\circ} \mathrm{C}^{-1}$, $Q_{\text {geo }}=1 \times 10^{-1} \mathrm{~W} \mathrm{~m}^{-2}$ (Goutorbe et al. 2011), and $c_{p}=3.9 \times$ $10^{3} \mathrm{~J} \mathrm{~kg}^{-1}{ }^{\circ} \mathrm{C}^{-1}$ ) results in a net transformation of $G_{\mathrm{geo}}=-1.2 \times$ $10^{-3} \mathrm{~Sv}$. As this is two orders of magnitude smaller than the estimated internal transformation, it will not be considered further.

\section{c. Summary}

A water-mass budget may be defined in terms of the convergence of lateral transport balanced by the combination of the transformation by internal processes, surface forcing and 
geothermal forcing. For the deep-water masses considered in this work, our estimates based on observations and values from preceding literature indicate that the water-mass transformation is dominated by internal processes, $99.5 \%$, with the remaining transformation stemming from geothermal heating, $0.5 \%$. These internal processes can be decomposed into dianeutral mixing, cabbeling, and thermobaricity. The internal transformation is primarily driven by mixing, $88 \%$, with smaller contributions from thermobaricity, $11 \%$, and cabbeling, $1 \%$.

As turbulent mixing is the leading contributor to water-mass transformation within the DWBC in the Orkney Deep, we now consider a simplified budget to apply to our observations, entailing a balance between the convergent transport and turbulent mixing:

$$
\Delta \Psi_{\text {lat }}=-M=-\frac{\partial G}{\partial \gamma}=-\frac{\partial}{\partial \gamma}\left[\iint_{\gamma} \frac{\partial}{\partial \gamma}\left(\frac{B_{f} \rho_{0} b}{g}\right) d A\right] .
$$

Taking the average of the buoyancy flux on isoneutrals $\left\langle B_{f}\right\rangle$ gives

$$
\Delta \Psi_{\text {lat }}=-\frac{\partial^{2}}{\partial \gamma^{2}}\left(\frac{\left\langle B_{f}\right\rangle \rho_{0} b A_{\gamma}}{g}\right)
$$

where $A_{\gamma}$ is the area of the isoneutral. Then, by integrating with respect to neutral density twice, we obtain

$$
\left\langle B_{f}\right\rangle=\langle\Gamma \epsilon\rangle=\frac{g}{\rho_{0} b A_{\gamma}} \iint-\Delta \Psi_{\text {lat }} d^{2} \gamma,
$$

This simplified budget is next applied to our observational data.

\section{Estimating the dianeutral transport from CTD/LADCP sections}

\section{a. Calculation of lateral and dianeutral transports}

We commence by considering the volume transport through the measured sections in neutral density bins. A range of bin sizes were tested, and overall results of the analysis were insensitive to the size of the bins. The analysis presented here uses bins of $\Delta \gamma=0.02 \mathrm{~kg} \mathrm{~m}^{-3}$. This choice is a compromise between ensuring that the bin is small enough to capture the details of the transport, and minimizing the noise caused by integrating over small extents that are suboptimally represented in the data.

The volume transport within a density bin of width $\Delta \gamma$ centered on $\gamma$ is given by

$$
\Psi_{\text {lat }}=\iint_{\gamma-(\Delta \gamma / 2)}^{\gamma+(\Delta \gamma / 2)} U_{\text {across }} \partial z \partial x
$$

where $U_{\text {across }}$ is the velocity normal to the section, with positive flow toward the Scotia Sea.

This transport is evaluated by interpolating the CTD/LADCP profiles of neutral density and horizontal velocity onto a grid with horizontal and vertical spacings of 250 and $2 \mathrm{~m}$. First, each individual profile is averaged in $2-\mathrm{m}$ vertical bins. Prior to horizontal interpolation, the velocity in bottom triangles between profiles is dealt with by extending the bottom velocity in each profile. The data are then horizontally linearly interpolated between the profiles and grid positions deeper than the local topography, given by a merged swath and General Bathymetric Chart of the Oceans (GEBCO) product (Abrahamsen 2019), are removed.

Before computing the volume budget, the lateral transports through each section are normalized to the average total lateral transport integrated over the full range of density (4.2 Sv), calculated from measurements at sections A, B, C + D, C + E, and $\mathrm{F}$. Characteristic lateral transport distributions in neutral density bins upstream and downstream of the Orkney Deep are then quantified by separately averaging normalized transport measurements for upstream $(\mathrm{C}+\mathrm{D}, \mathrm{C}+\mathrm{E}$, and $\mathrm{F})$ and downstream (A and B) sections. Our approach of averaging sections seeks to reduce the impact of sampling biases (e.g., aliasing of high-frequency temporal variability, section 2a) in individual sections. The differences between the lateral transports within each neutral density bin between the (normalized) average upstream and downstream transport profiles is then indicative of the convergence of the lateral transport.

The dianeutral transport and buoyancy flux are calculated by integrating the convergence of the lateral transport within neutral density bins, up from the bottom, with the assumption that the dianeutral transport and buoyancy flux are both zero at the maximum density within Orkney Deep. The uncertainty in these dianeutral transport and buoyancy flux diagnostics is estimated using a Monte Carlo approach, on the premise that the main source of error in our calculations is the aliasing of temporal variability by our "snapshots." A total of 10000 realizations were generated with an error applied to each density bin. This error was produced pseudorandomly, following a normal distribution with a standard deviation equal to the high-frequency (on periods shorter than 30 days) variability in neutral density-binned lateral transports measured by the moorings.

\section{b. Observed lateral and implied dianeutral transports}

The lateral transports through the sections in neutral density space exhibit differences associated both with changes in the total transport (Fig. 5a) and changes in the distribution of the transport (Fig. 5b). The sections upstream of the Orkney Deep (red-shaded lines in Fig. 5) show a broad lateral transport in neutral density space, with the transport in sections $\mathrm{D}, \mathrm{E}$ and $\mathrm{F}$ occurring throughout the neutral density range from 28.1 to $28.43 \mathrm{~kg} \mathrm{~m}^{-3}$ and no individual density bin accounting for more than $15 \%$ of the transport. This does not apply to section C, since only a small portion of the flow (focused on the lighter classes) intersects this section, with only $18 \%$ and $16 \%$ of the total lateral transport when combined with sections $\mathrm{D}$ and $\mathrm{E}$ (Table 1) to cover the entire flow (Fig. 1). In contrast, sections downstream of Orkney Deep (blue-shaded lines in Fig. 5) display a lateral transport that is much more focused in neutral density space, with no transport denser than $28.37 \mathrm{~kg} \mathrm{~m}^{-3}$ and several individual density bins accounting for more than $20 \%$ of the total transport. This focusing of the lateral transport in Orkney Deep is now explored using the volume budget set out in section 4. 


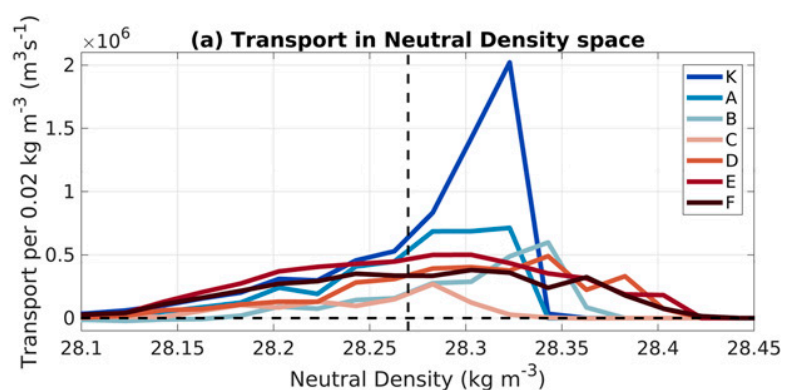

(b) Proportion of Transport in Neutral Density space

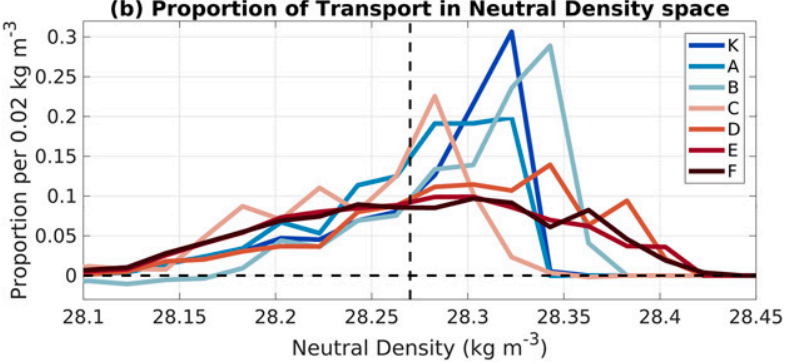

FIG. 5. Lateral volume transports through the observed sections in neutral density bins of $0.02 \mathrm{~kg} \mathrm{~m}^{-3}$. Transports are presented both as (a) dimensional transports in $\mathrm{m}^{3} \mathrm{~s}^{-1}$ and (b) as a proportion of the total transport through the section. The horizontal dashed line indicates zero volume transport, and the vertical dashed line marks a neutral density of $28.26 \mathrm{~kg} \mathrm{~m}^{-3}$, which is used as the upper boundary of the AABW.

The average lateral transports upstream and downstream of Orkney Deep exhibit the same signal of a focusing in neutral density space as above. The focusing significantly exceeds the temporal variability in the neutral density distribution of the transport from the mooring data (shaded area in Fig. 6a), and thus is interpreted as lateral transport convergence within Orkney Deep. This convergence is taken as a net formation within Orkney Deep, given the steady-state assumption. A negative formation, i.e., a net convergence or destruction of volume, occurs in the densest classes, of up to $M=-0.23 \mathrm{~Sv}$ per $0.02 \mathrm{~kg} \mathrm{~m}^{-3}$. There is a positive formation, i.e., a net divergence or production of volume, on lighter layers, reaching a peak of $M=0.49 \mathrm{~Sv}$ per $0.02 \mathrm{~kg} \mathrm{~m}^{-3}$ at $28.32 \mathrm{~kg} \mathrm{~m}^{-3}$. Both of these signals are larger than the temporal variability present in the mooring data, which is typically \pm 0.08 to $0.18 \mathrm{~Sv}$ per $0.02 \mathrm{~kg} \mathrm{~m}^{-3}$, providing confidence that these convergences are not the result of aliasing temporally variable signals (Fig. 6b).

The loss of water in the densest classes, combined with the requirement that the dianeutral transport be zero at a class with zero surface area, implies a net lightening of the densest water, i.e., a negative dianeutral transport. This lightening is insufficient to provide the observed gain of volume on lighter layers, so there must be some densification of lighter water. This means that the gain of volume at intermediate densities, the focusing of the lateral transport in the Orkney Deep, is driven by a combination of lightening of dense water and densification of lighter water (Fig. 6c). The implied dianeutral transports are substantially larger, $0.5 \mathrm{~Sv}$, than our initial estimate of the mixing-driven transformation, $0.2 \mathrm{~Sv}$ [section $5 \mathrm{a}(1)$ ].
The reasons for this difference will be explored by considering the water-mass transformation framework in the next section.

\section{Linking the dianeutral transport to mixing-driven water-mass transformation}

The dianeutral transport characterized in the previous section is underpinned by transformation driven by turbulent dianeutral mixing (section 5). This relationship will be made explicit by diagnosing the mixing-driven buoyancy flux from the dianeutral transport, area of isoneutrals, and ratio of neutral density to potential density gradients, following Eq. (16).

\section{a. Area of isoneutrals}

The area of isoneutrals is calculated using the hydrographic fields from the model (section $2 b$ ). The assumption is made that the isoneutral area is well approximated by the horizontal area where that neutral density exists. The area is calculated using a subregion of the model, bounded by sections $\mathrm{B}, \mathrm{C}$, and $\mathrm{D}$, and the topography. This gives isoneutral areas up to a maximum of $A_{\gamma}=9.8 \times 10^{9} \mathrm{~m}^{2}$ at a neutral density of $28 \mathrm{~kg} \mathrm{~m}^{-3}$. The isoneutral area at a neutral density of $28.27 \mathrm{~kg} \mathrm{~m}^{-3}$ is $A_{\gamma}=8 \times 10^{9} \mathrm{~m}^{2}$, reducing to $A_{\gamma}=4 \times 10^{9} \mathrm{~m}^{2}$ at $28.4 \mathrm{~kg} \mathrm{~m}^{-3}$. Isoneutral areas were also calculated taking the area of Orkney Deep and scaling by the length of the isoneutrals from the observed sections at the inflow. This agreed well with the model calculation.

\section{b. Ratio of density gradients}

The ratio of vertical gradients in neutral density and locally referenced potential density is calculated from the observational data with a neutral density greater than $28.2 \mathrm{~kg} \mathrm{~m}^{-3}$ in sections $\mathrm{B}, \mathrm{C}$, and $\mathrm{D}$. The ratio is computed locally using each pair of gradients. The average ratio is $b=2.17$, with an interquartile range of 1.99-2.49. The ratio of $b=2.17$ will be used in the following sections, which may introduce an error of up to $12 \%$.

\section{c. Buoyancy flux}

Using these isoneutral areas and density gradients, a profile of the isoneutral-averaged buoyancy flux can be calculated [Eq. (16)]. The budget implies a maximum buoyancy flux of $B_{f}=1 \times 10^{-8} \mathrm{~W} \mathrm{~kg}^{-1}$ at $28.33 \mathrm{~kg} \mathrm{~m}^{-3}$. The buoyancy flux reduces either side of this, to $B_{f}=1 \times 10^{-9}$ at $28.39 \mathrm{~kg} \mathrm{~m}^{-3}$ and $B_{f}=4 \times 10^{-9} \mathrm{~W} \mathrm{~kg}^{-1}$ at $28.27 \mathrm{~kg} \mathrm{~m}^{-3}$ (Fig. 6d). As a result of integrating up from the densest class, the errors accumulate on lighter classes, which are more distant from the zero-buoyancy flux at the bottom of the basin. Due to this accumulation, the errors become sufficiently large for classes lighter than $28.27 \mathrm{~kg} \mathrm{~m}^{-3}$ that the buoyancy flux cannot be distinguished from zero.

\section{d. What is the value of the dissipation ratio?}

The dissipation ratio $\Gamma$ characterizing the water-mass transformation in the Orkney Deep is calculated next. First, a bulk estimate is obtained by comparing the buoyancy flux computed from the water-mass budget to area-averaged microstructure estimates of the TKE dissipation rate $\epsilon$. Subsequently, a local 

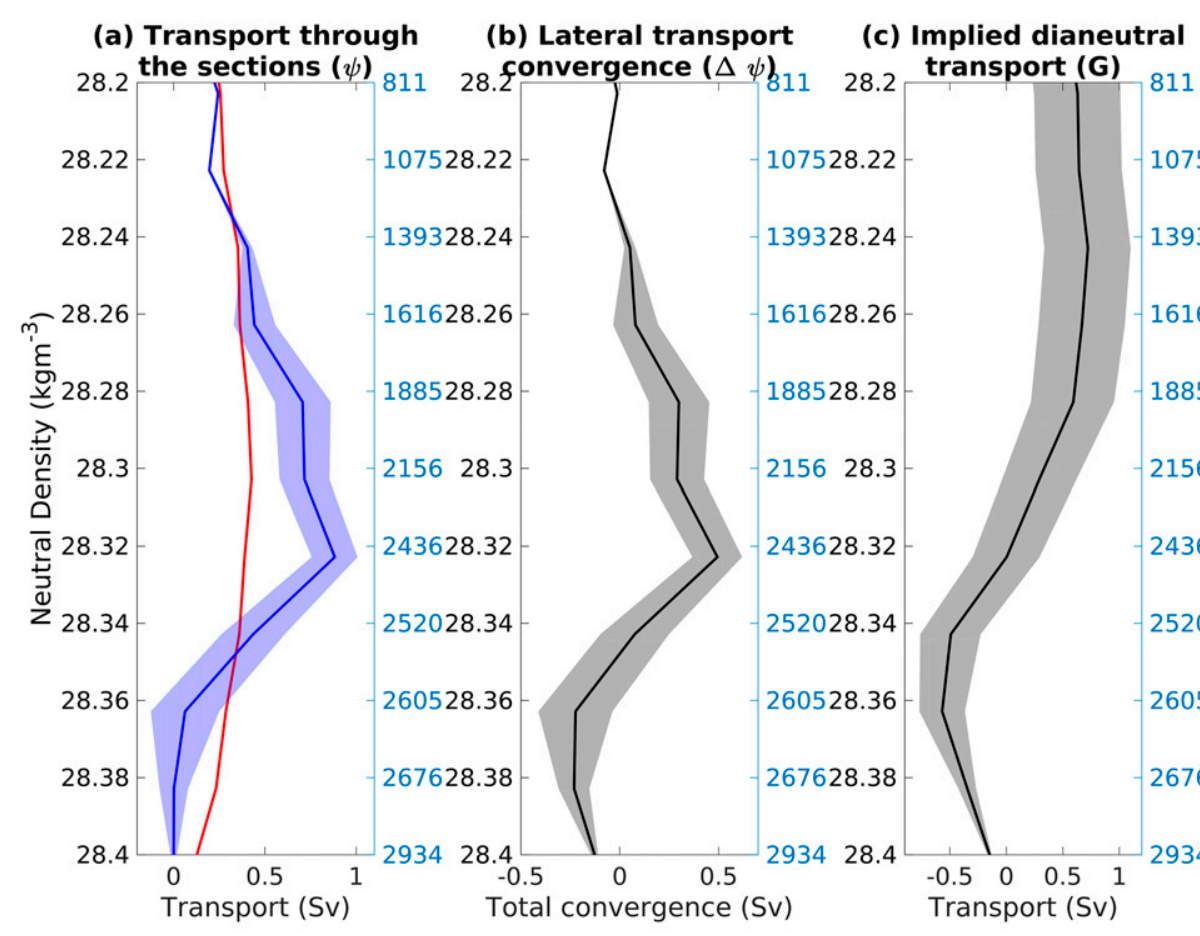
(d) Inferred Buoy
Flux $\left(\left\langle\mathbf{B}_{\mathbf{f}}\right\rangle\right)$
28.2

yancy transport (G) 811 811

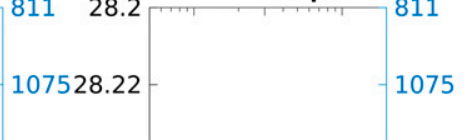
\begin{tabular}{l|l|l|}
$139328.24-139328.24$ & -1393
\end{tabular} 161628.26 - $\quad-161628.26-1616$

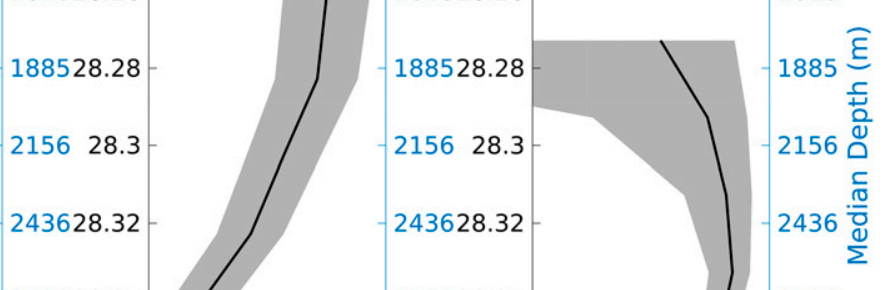

FIG. 6. Components of the volume and water-mass budget for the Orkney Deep. (a) The average volume transport in density bins for the sections upstream (red) and downstream (blue) of the Orkney Deep; (b) the convergence of the flow within the Orkney Deep, where positive indicates a net outflow of volume or an implied production of volume; (c) the implied dianeutral transport within the Orkney Deep, where positive indicates water moving toward denser classes; and (d) the implied buoyancy flux required to generate the dianeutral transport diagnosed from the volume budget, assuming the transformation to be exclusively driven by mixing. In all panels, the shading is the $95 \%$ bootstrap confidence interval, with errors based on the temporal variability of transports in the mooring observations. The median depth of isoneutrals is taken from observed density at section D.

view of $\Gamma$ is derived from collocated profiles of shear and temperature microstructure.

\section{1) BulK estimate}

A bulk estimate of $\Gamma$ is made by taking the ratio of the buoyancy flux underpinning water-mass transformation in the Orkney Deep (section 6c) and a regional $\epsilon$ profile derived by gridding in neutral density bins, and area-averaging, the shear microstructure measurements of the TKE dissipation rate (Fig. 1). A 95\% bootstrap confidence interval is calculated from the observed dissipation for each bin. Given the error accumulation in lighter bins, we will only consider classes denser than $28.27 \mathrm{~kg} \mathrm{~m}^{-3}$ to calculate the dissipation ratio.

The regional TKE dissipation profile exhibits values ranging from $\epsilon=9 \times 10^{-10} \mathrm{~W} \mathrm{~kg}^{-1}$ to $\epsilon=2 \times 10^{-8} \mathrm{~W} \mathrm{~kg}^{-1}$ (Fig. 7a). This, combined with the budget-derived estimates of the buoyancy flux, implies a range of dissipation ratios from 0.46 to 4.08 , with an interquartile range of $0.60-1.08$ (Fig. 7a). These dissipation ratios substantially exceed the canonical value for stratified shear turbulence, $\Gamma=0.2$ (Gregg et al. 2018).

\section{2) Local estimate}

The dissipation ratio can also be calculated locally using the microstructure data. This approach entails computing the buoyancy flux from the microstructure estimates of temperature variance dissipation, by assuming that the diffusivity of temperature and density are the same (Gregg et al. 2018). This is the case where turbulent diffusion is larger than molecular diffusion. In our study area, the turbulent diffusivity from the observations, $>10^{-2} \mathrm{~m}^{2} \mathrm{~s}^{-1}$ in the bottom $1000 \mathrm{~m}$, is much larger than the molecular diffusivities, $10^{-7} \mathrm{~m}^{2} \mathrm{~s}^{-1}$, most likely as a result of a range of instabilities triggered by the interaction of the DWBC's flow with the bottom boundary (Naveira Garabato et al. 2019). The buoyancy flux can thus be estimated as

$$
B_{f}=\frac{\chi N^{2}}{2\left(\frac{\partial \theta}{\partial z}\right)^{2}},
$$

where $\chi$ is the temperature variance dissipation rate, $N^{2}$ is the buoyancy frequency, and $\theta$ is potential temperature. This buoyancy flux can be compared to the TKE dissipation rate from the microstructure shear observations to estimate the dissipation ratio [Eq. (8)]. We conduct this calculation for the deep-water layers in the Orkney Deep, using 200-m vertical bins. Additionally, we exclude regions where the temperaturesalinity diagram is not linear or exhibits large spread, so as to avoid the scenario in which the temperature variance budget is substantially modified by isoneutral stirring. This selection was 

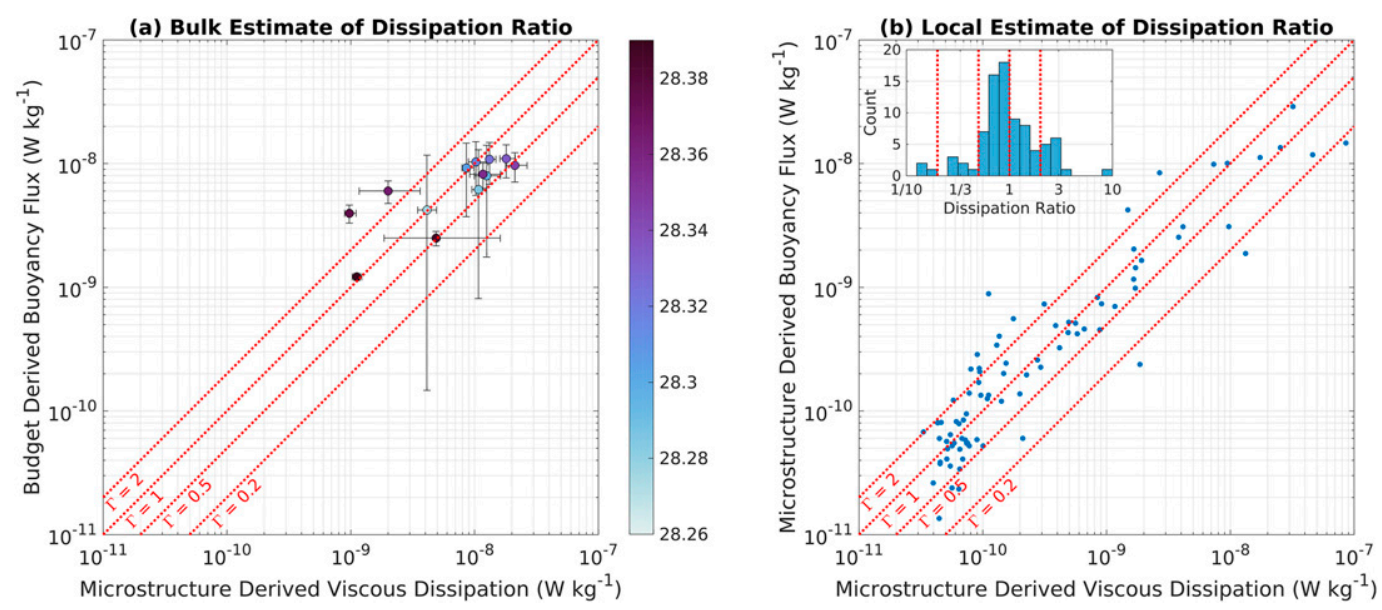

FIG. 7. Scatterplots showing the relationship between the buoyancy flux and the turbulent kinetic energy dissipation rate. (a) The buoyancy flux is taken from the water-mass budget, and the dissipation rate is taken from microstructure profiles averaged in the same density bins. (b) The buoyancy flux is derived from the micro- and finestructure temperature observations, and the dissipation is taken from microstructure profiles, both calculated in $100-\mathrm{m}$ vertical bins. The inset in (b) is a histogram of the dissipation ratio from the microstructure data. In all panels, the dashed red lines indicate dissipation ratios of $0.2,0.5,1$, and 2 .

performed using visual inspection, and yielded a total of 85 estimates of the dissipation ratio.

The buoyancy flux diagnosed from the microstructure data spans several orders of magnitude, from $B_{f}=10^{-11}$ to $10^{-7} \mathrm{~W} \mathrm{~kg}^{-1}$ (Fig. 7b). The same range is also seen in the TKE dissipation rate averaged in the same bins. These ranges are larger than those obtained from the water-mass budgetderived buoyancy flux and TKE dissipation rate, as a result of the smaller bins in the present $\Gamma$ estimate maintaining more of the observed variability. Local values of the dissipation ratio range from 0.1 to 10 . The majority of the estimates are clustered between 0.66 and 1.35 (Fig. 7b, inset), with an average value of 0.94 . However, as all these turbulent patches may not equally contribute to the total buoyancy flux (since some patches are more energetic than others), the average dissipation ratio may be recomputed with weighting by the viscous dissipation of each patch, yielding 0.53 . This weighted average is primarily derived from a small number of highly energetic events ( $78 \%$ of the total viscous dissipation is supplied by 5 out of 85 turbulent patches), and so has a potentially large sampling error. The weighted average is slightly smaller than the initial average dissipation ratio, suggesting that the dissipation ratio of the more energetic events is lower than the dissipation ratio of less energetic events in our observations. The weighted average is, in any case, still significantly larger than the canonical value of 0.2 , consistent with results from the watermass budget.

\section{Discussion}

The results presented in sections 6 and 7 corroborate our starting expectation that the Orkney Deep is a region of intense water-mass transformation, and reveal that this is underpinned by vigorous turbulence (denoted by elevated TKE dissipation rates) with a high mixing efficiency (indicated by large values of the dissipation ratio). In the following, we will complete the test of our starting hypothesis by showing that the water-mass transformation, vigorous turbulence and efficient mixing documented here are associated with the DWBC's interaction with the sloping boundary.

\section{a. Controls on the magnitude and structure of water-mass transformation}

The diagnosed dianeutral transport in the Orkney Deep is disproportionately large (peaking at $0.5 \mathrm{~Sv}$ ) for the basin's area when compared to global water-mass budgets (Talley 2013), and has a distinct structure associated with a lightening of the densest water and a densification of the lighter classes of AABW. This leads to a focusing of volume transport in density space. Next, we elucidate which aspects of the mixing-driven transformation are responsible for the dianeutral transport's magnitude and structure. This will be achieved by combining the observed turbulent diffusivity and the density field from the numerical model with a decomposition of the transformation. Note that, while there are some differences between the observed and modeled density structure and stratification at depth, the model exhibits a convergence of the lateral transport with a similar vertical structure to the observations, albeit slightly weaker (a convergence of $0.5 \mathrm{~Sv}$ in the observations versus $0.35 \mathrm{~Sv}$ in the model, at $28.36 \mathrm{~kg} \mathrm{~m}^{-3}$ ). This is likely a result of the model's stratification being smoother than observed (Fig. 3).

Using Eqs. (4) and (6) and averaging on isoneutrals, the transformation $G$ is linked to turbulent mixing by

$$
G=-\frac{\partial}{\partial \gamma}\left(\iint_{\gamma} \kappa_{\perp} \frac{\partial \gamma}{\partial z} \partial A\right) \approx-\frac{\partial}{\partial \gamma}\left(\left\langle\kappa_{\perp}\right\rangle\left\langle\frac{\partial \gamma}{\partial z}\right\rangle\langle A\rangle\right),
$$

where \langle\rangle indicates an average on an isoneutral.

This transformation may be partitioned into three contributions, 

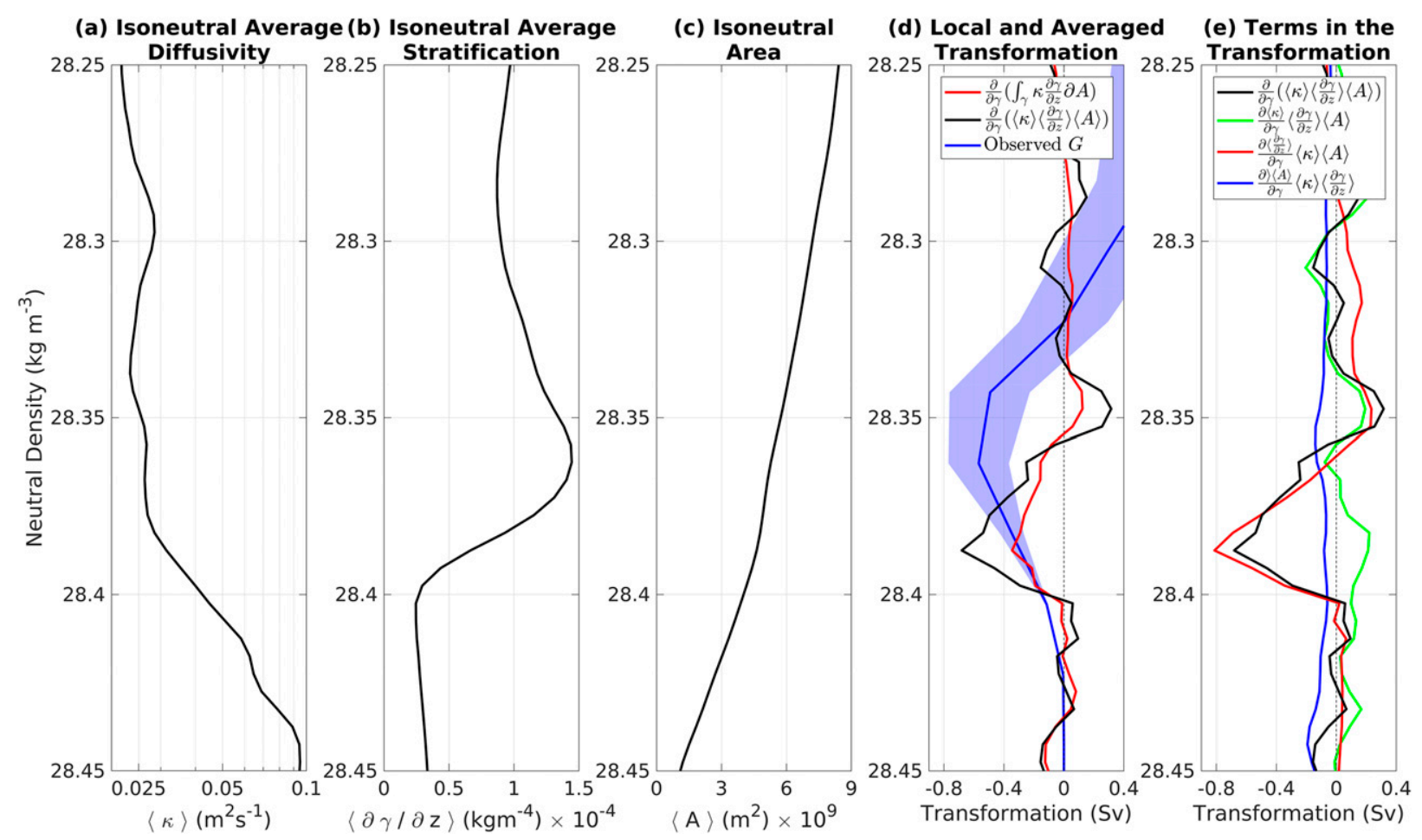

FIG. 8. Profiles in neutral density space of (a) average diffusivity on isoneutrals, (b) average stratification on isoneutrals, (c) area of isoneutrals, (d) implied water-mass transformation from the local (red) and average approaches (blue), and (e) terms contributing to water-mass transformation in the average approach. These profiles are constructed using the neutral density field from the high-resolution numerical model and the observed diffusivity averaged in height-above-bed coordinates. The dianeutral velocity from the observational budget, equivalent to Fig. 6c, is also shown in (d) in blue for comparison.

$$
G \approx-\frac{\partial\left\langle\kappa_{\perp}\right\rangle}{\partial \gamma}\left\langle\frac{\partial \gamma}{\partial z}\right\rangle\langle A\rangle-\left\langle\kappa_{\perp}\right\rangle \frac{\partial\left\langle\frac{\partial \gamma}{\partial z}\right\rangle}{\partial \gamma}\langle A\rangle-\left\langle\kappa_{\perp}\right\rangle\left\langle\frac{\partial \gamma}{\partial z}\right\rangle \frac{\partial\langle A\rangle}{\partial \gamma} .
$$

Here, the diffusivity $\left\langle\kappa_{\perp}\right\rangle$ and isoneutral area $\langle A\rangle$ are both, by definition, positive. The stratification $\langle\partial \gamma / \partial z\rangle$ is also typically positive, with patches of negative stratification often being rapidly removed by gravitational instability. Thus, as each of these terms are typically positive, the key to understanding the structure of the transformation is the sign of the gradients. There are three terms, whose sign is controlled by the gradients of diffusivity $\partial\left\langle\kappa_{\perp}\right\rangle / \partial \gamma$, stratification $\partial\langle\partial \gamma / \partial z\rangle / \partial \gamma$, and isoneutral area $\partial\langle A\rangle / \partial \gamma$. A similar decomposition was recently applied to an idealized numerical simulation (Drake et al. 2020). We now assess which term(s) underpin the magnitude and structure of the transformation in the Orkney Deep. We do this by considering the average height-above-bed profile of diffusivity from the observations (Fig. 2) and the neutral density field from the numerical model.

The diffusivity profile denotes an increase in the intensity of mixing with increasing neutral density, from $\left\langle\kappa_{\perp}\right\rangle=0.02 \mathrm{~m}^{2} \mathrm{~s}^{-1}$ at $\gamma=28.25 \mathrm{~kg} \mathrm{~m}^{-3}$ to $\left\langle\kappa_{\perp}\right\rangle=0.95 \mathrm{~m}^{2} \mathrm{~s}^{-1}$ at $\gamma=28.45 \mathrm{~kg} \mathrm{~m}^{-3}$ (Fig. 8a). This results from the denser surfaces being close to the bottom boundary, where diffusivity is enhanced (Fig. 2c), over a larger proportion of their area. In turn, the stratification profile exhibits high density gradients on lighter surfaces, $\langle\partial \gamma / \partial z\rangle=0.98 \times 10^{-4} \mathrm{~kg} \mathrm{~m}^{-4}$ at $\gamma=28.25 \mathrm{~kg} \mathrm{~m}^{-3}$, and a decrease of stratification with depth, $\langle\partial \gamma / \partial z\rangle=0.4 \times 10^{-4} \mathrm{~kg} \mathrm{~m}^{-4}$ at $\gamma=28.45 \mathrm{~kg} \mathrm{~m}^{-3}$ (Fig. 8b). This is indicative of a transition from strong stratification in the main pycnocline to weak stratification at depth. Superimposed on this large-scale pattern, there is a local maximum in stratification around a neutral density of $28.36 \mathrm{~kg} \mathrm{~m}^{-3}$. This maximum is associated with the isoneutral intersecting the core of the inflow into Orkney Deep, and may result from the DWBC advecting stratified water into the basin while the stratification in the surrounding water is eroded by mixing. Finally, the area of isoneutrals decreases with depth from $\langle A\rangle=8 \times 10^{9} \mathrm{~m}^{2}$ at $\gamma=28.25 \mathrm{~kg} \mathrm{~m}^{-3}$ to $\langle A\rangle=1.4 \times$ $10^{9} \mathrm{~m}^{2}$ at $\gamma=28.45 \mathrm{~kg} \mathrm{~m}^{-3}$ (Fig. 8c). This reflects the bowl shape of the Orkney Deep, such that the reduction of the basin's horizontal cross-section with depth maps onto isoneutrals.

Before applying the decomposition in (19), we evaluate the extent to which the approximation in (18) holds. We calculate the transformation in two ways: one by taking the local buoyancy flux and integrating on isoneutrals [equivalent to the second equality in (19)], and the other by taking the average stratification and diffusivity on isoneutrals [equivalent to the third equality in (19)]. The local buoyancy flux-based calculation is more complete, as it accounts for covariances of diffusivity and stratification on an isoneutral, whereas the average perspective assumes these covariances to be small. 
The transformation calculated using the local approach with the model density indicates a lightening of up to $G=0.35 \mathrm{~Sv}$ in the neutral density range $28.4-28.35 \mathrm{~kg} \mathrm{~m}^{-3}$ (red line in Fig. 8d). On isoneutrals lighter than $28.35 \mathrm{~kg} \mathrm{~m}^{-3}$, there is a weak but persistent densification. This lightening of dense waters is of similar magnitude and structure as diagnosed from the observed volume budget, although shifted toward denser surfaces (Fig. 8d); however, the densification is weaker than the observed budget. This is likely a result of the way the observed diffusivity profile, which exhibits a bottom intensification in the deepest $1000 \mathrm{~m}$ and little vertical structure above (Fig. 2c), was applied to the model. The lack of vertical structure in the observed diffusivity profile higher in the water column may stem from the observations being primarily located on the sides of the basin, thereby missing the weak midwater column mixing expected in deeper parts of the basin.

The transformation from the average perspective reproduces the approximate magnitude and structure of the local buoyancy flux-based transformation. The lightening of waters in the $28.35-28.4 \mathrm{~kg} \mathrm{~m}^{-3}$ neutral density class is well represented (black versus red in Fig. 8d), although there is a mismatch in the magnitude. This is unsurprising, as there is likely to be some covariability between the diffusivity and the stratification that would likely be manifested near the boundaries, where stratification is weaker and the diffusivity higher than the isoneutral average. The densification of the lighter classes of AABW is not recovered by the average perspective. All in all, the extent of agreement between the transformation estimated from the water-mass budget (Fig. 8d, blue line), the local approach (Fig. 8d, red line) and the average perspective (Fig. 8d, black line) is sufficient to expect that the decomposition in (19) will yield useful information on the factors controlling the transformation.

The contributions to the transformation by the three terms on the right hand side of (19) are shown in Fig. 8e. The effect of dianeutral changes in diffusivity (green line) is to drive a densification of, typically, $G_{\text {diff }}=0.02-0.21$ Sv through much of the AABW. The effect of the shrinking area of isoneutrals with density, referred to as hypsometry (blue line), leads to a net lightening from $G_{\text {area }}=-0.07$ to $-0.18 \mathrm{~Sv}$ within the $\mathrm{AABW}$ layer. Both of these terms have been widely explored in the literature (St. Laurent et al. 2001; de Lavergne et al. 2016b) and, in the case of the Orkney Deep, broadly cancel each other, leading to limited net transformation. The final term, linked to dianeutral changes in the stratification (red line), is primarily responsible for the magnitude and structure of the total transformation (black line). This is especially true of the lightening of AABW in the neutral density range 28.35$28.4 \mathrm{~kg} \mathrm{~m}^{-3}$ (Fig. 8e). The importance of variations in stratification in controlling deep-ocean water-mass transformation has also been identified in idealized numerical simulations (Drake et al. 2020).

The reduction in stratification with density is likely to result from several factors combined, including intensified mixing near the bottom, but also different water-mass trajectories and advective factors. Mixing-driven reduction in stratification is unlikely to lead to the transformation seen here, as the transformation requires enhanced mixing to act on a sharp gradient, which would be eroded if the only process controlling the stratification was mixing. There are two possible advective factors that could underpin the reduction in stratification with increasing neutral density shaping the transformation. The first is that the highest stratification is in the main pycnocline and reduces with depth, as a result of large-scale drivers (Nikurashin and Vallis 2011, 2012). The second is that, in DWBCs such as that crossing the Orkney Deep, weak stratification is expected to be generated by a downslope (to the right of the DWBC) Ekman flow near the sloping boundary (Brink and Lentz 2010). This bottom Ekman flow advects light water under denser water, thereby producing a bottom boundary layer of reduced stratification adjacent to topography. Such a feature is indeed observed underlying the DWBC in the Orkney Passage, where $N^{2}$ values below $10^{-7} \mathrm{~s}^{-2}$ and downslope flows on the order of a few centimeters per second are common (Naveira Garabato et al. 2019). The bottom Ekman-induced reduction in stratification could be particularly important for transformation on isoneutrals where there is a substantial dianeutral change in the proportion of the isoneutral embedded within the bottom boundary layer, or in the intensity of the downslope flow beneath the DWBC. In the Orkney Deep, the strongest lightening occurs in a narrow neutral density band, $28.35-28.4 \mathrm{~kg} \mathrm{~m}^{-3}$, relative to the largescale reduction in stratification with depth, $28.15-28.4 \mathrm{~kg} \mathrm{~m}^{-3}$ (Fig. 8e). The $28.35-28.4 \mathrm{~kg} \mathrm{~m}^{-3}$ range is collocated with the steepest decline in stratification and the dense side of the DWBC (Figs. 5 and $8 \mathrm{~b}$ ). This combination indicates that the most likely driver of water-mass transformation in the Orkney Deep is the downslope bottom Ekman flow, rather than the large-scale decline in stratification.

The importance of dianeutral gradients in stratification in shaping the magnitude and structure of transformation in the Orkney Deep highlights the key role of processes determining the density field near the sloping boundary. The balance between destratifying and restratifying processes in flow regimes conducive to downslope bottom Ekman transport (such as our DWBC) has attracted recent attention in the literature (Callies 2018; Wenegrat et al. 2018; Naveira Garabato et al. 2019). These studies show that destratification by the bottom Ekman flow can generate large lateral and vertical shears near the topography that are favorable to the development of centrifugal, symmetric and baroclinic instabilities. The ensuing ageostrophic motions act to restore near-boundary stratification and promote the lateral exchange of well-mixed bottom boundary waters with stratified off-boundary waters, propagating the effects of near-boundary mixing into the interior. Recent observations from a mooring in the DWBC immediately downstream of the Orkney Passage (K. Polzin et al. 2021, unpublished manuscript) indicate that the near-boundary restratification may take the form of a tidally forced "internal swash," entailing a diurnal, rapid flattening of near-vertical isoneutrals by dense water rushing upslope. Regardless of the specific phenomenology involved, the local balance between destratification and restratification processes near the sloping boundary beneath DWBCs is likely to be magnified and propagated through their role in determining the magnitude and structure of the transformation. 

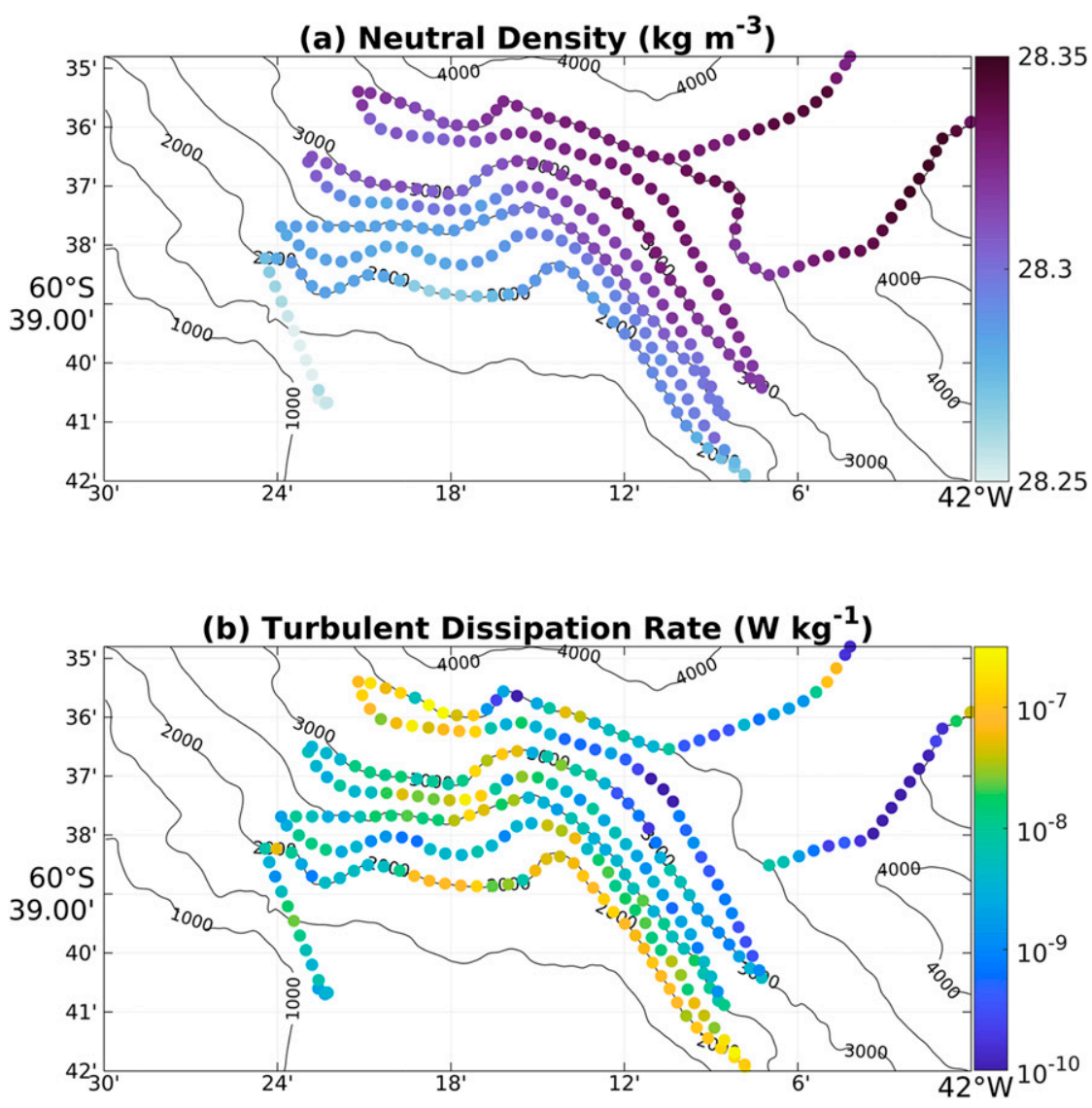

FIG. 9. Maps showing (a) the neutral density and (b) the turbulent kinetic energy dissipation rate measured by ALR between 60 and $140 \mathrm{~m}$ above the seabed.

A final point of note is that, while our conceptualization of the transformation is based on assuming that a single profile of diffusivity can be applied across the Orkney Deep, the transformation may also be influenced by the occurrence of covariability in the cross-slope distributions of bottom neutral density and buoyancy flux. Such covariability would lead to a transformation directed toward the isoneutral hosting the maximum buoyancy flux. Our observations suggest that this is likely to contribute to lightening of the denser waters beneath the DWBC in the Orkney Deep. For example, considering the ALR dataset around the downstream end of the Orkney Deep, there is a region to the east of $42^{\circ} 12^{\prime} \mathrm{W}$ in which TKE dissipation (and thus buoyancy flux) increases, from $\epsilon=10^{-9}$ to $10^{-7} \mathrm{~W} \mathrm{~kg}^{-1}$, on the shallower isobaths (Fig. 9b). This results in a cross-slope gradient in the buoyancy flux that maps onto the gradient in near-bottom neutral density, from $\gamma=28.28 \mathrm{~kg} \mathrm{~m}^{-3}$ at a depth of $2000 \mathrm{~m}$ to $\gamma=28.33 \mathrm{~kg} \mathrm{~m}^{-3}$ at $3000 \mathrm{~m}$ (Fig. 9a). Substituting these gradients in (7) implies an upwelling velocity of $w_{\text {mix }}=-4 \times 10^{-4} \mathrm{~m} \mathrm{~s}^{-1}$. If we now assume that this process acts on a 500-m-thick layer (Fig. 2) along the 200-km-long southern flank of the Orkney Deep, a lightening of $G_{\mathrm{mix}}=-0.04 \mathrm{~Sv}$ is obtained. This is weaker than the transformation associated with the curvature of isoneutrals, but is similar in magnitude to the effects of bottomintensified mixing and hypsometry.

\section{b. Why is turbulent mixing in the Orkney Deep so efficient?}

Our inferred dissipation ratio, characterizing the efficiency of mixing in the Orkney Deep and estimated at 0.6-1.35, substantially exceeds the value of 0.2 that has traditionally been assumed to apply to oceanic turbulence. This result resonates with a number of recent studies, primarily numerical, but also observational, proposing that the dissipation ratio in the ocean depends on the buoyancy Reynolds number, which measures the relative importance of the turbulence mixing buoyancy vertically and being suppressed by stratification and viscosity (Mashayek et al. 2017). Nonetheless, our value exceeds the range of dissipation ratios $(0.05-0.45)$ predicted by such studies (de Lavergne et al. 2016a; Mashayek et al. 2017; Gregg et al. 2018). The reason for this difference is likely to stem from the distinct phenomenology of turbulent mixing in the Orkney Deep compared to previous investigations.

Those investigations have focused on unraveling turbulence generated by velocity shear in the presence of stratification, where the shear undergoes Kelvin-Helmholtz (KH) instability that fully develops and ultimately dissipates (e.g., Mashayek and Peltier 2013; Salehipour et al. 2015; 
Kaminski and Smyth 2019). In this scenario, KH instability takes several buoyancy periods to grow and drive turbulent mixing. However, in regions of weak stratification, like the Orkney Deep, the lifespan of a KH instability can exceed the time scale of the variability in the forcing [see K. Polzin et al. (2021, unpublished manuscript) for details], such that $\mathrm{KH}$ instabilities cannot fully develop. The end result of this arrested $\mathrm{KH}$ development could be an enhancement of the dissipation ratio through three suggested routes, which will be explored in future work:

1) If the role of $\mathrm{KH}$ instability in resetting the ratio of potential to kinetic energy in the turbulent cascade was inefficient, as could occur from the instability's arrested development, a direct cascade from forcing to dissipative scales could ensue. The dissipation ratio would then be set at the production scale (K. Polzin et al. 2021, unpublished manuscript).

2) Alternatively, the variability in the forcing could increase the contribution of young $\mathrm{KH}$ instabilities to the total dissipation, as the forcing changes prior to the instabilities reaching maturity. Young $\mathrm{KH}$ instabilities are typically viewed as a small contribution to the dissipation, but are characterized by larger dissipation ratios than older instabilities (Smyth et al. 2001).

3) Finally, the source of mixing within the DWBC could be unrelated to shear instability, and instead be associated with convection induced by downslope bottom Ekman flows (e.g., Naveira Garabato et al. 2019). Convective instabilities are known to have large dissipation ratios, 0.75 for Rayleigh-Taylor instability (Davies Wykes and Dalziel 2014), and 0.5 for Rayleigh-Bénard convection (Gayen et al. 2013).

While the data presented here do not enable us to assess these potential processes, it is likely that the highly efficient mixing in the Orkney Deep is related to the presence of the DWBC, as it is the current's interaction with the basin's steep slope that generates (via downslope bottom Ekman flows) the weak near-boundary stratification preconditioning each of the efficient mixing pathways. The resulting high dissipation ratio in regions of weak stratification stands in contrast with the parameterizations used in numerical models, where the dissipation ratio is reduced for weak stratification (Melet et al. 2013).

\section{Conclusions}

The rate, structure, and processes of the water-mass transformation in a small Southern Ocean basin (the Orkney Deep) crossed by a DWBC conveying AABW has been assessed using a combination of observations and a high-resolution numerical model. We have shown that the Orkney Deep hosts intense dianeutral volume transports of up to $0.5 \mathrm{~Sv}$ that are disproportionate to the small basin area. Such transports entail a dianeutral convergence of the densest and lightest AABW classes at intermediate densities, associated with respective lightening and densification of the densest and lightest waters. These dianeutral transports can be linked to water-mass transformation, which is (a) Contributions to the transformation

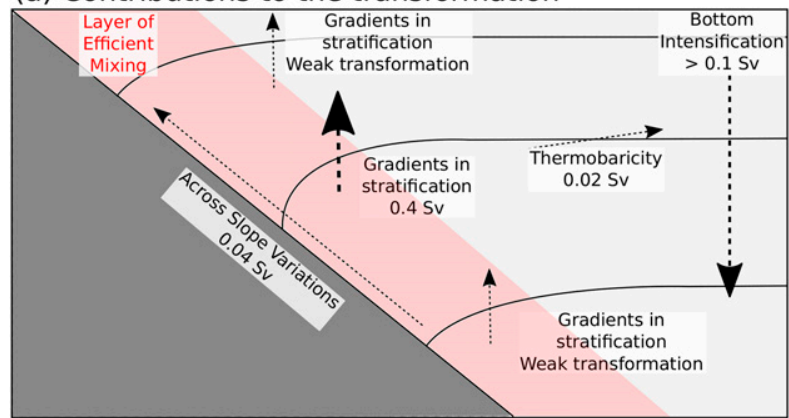

(b) Processes controlling the stratificaiton

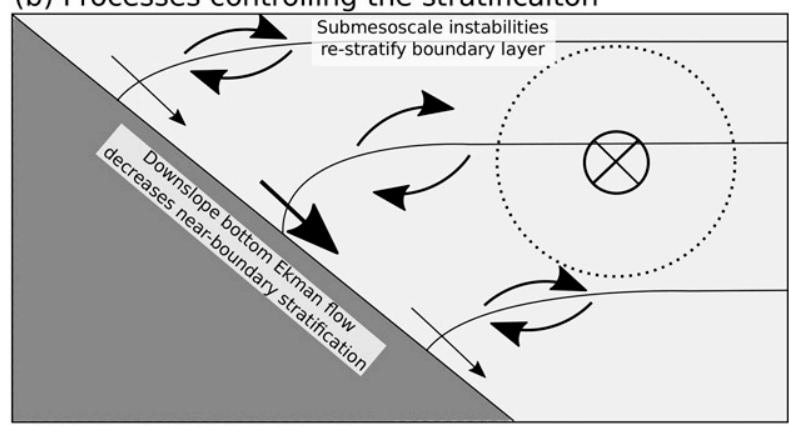

FIG. 10. Schematics of the DWBC in the Orkney Deep showing (a) the contributions to the water-mass transformation and (b) the processes determining the stratification near the boundary. In these schematics, the dashed lines indicate transformation driven by mixing, and solid arrows denote advective processes.

primarily driven by turbulent mixing and is most vigorous at the base of the DWBC flow over the sloping boundary of the basin. Thus, water-mass transformation in the Orkney Deep is primarily underpinned by near-boundary turbulent mixing.

A more detailed inspection of the drivers of the transformation reveals that, whereas the densification of the lightest AABW classes is associated with the intensification of turbulent mixing with depth, the lightening of the densest classes is induced by turbulence acting on the relatively abrupt transition from a weakly stratified boundary layer to well-stratified offboundary waters (Fig. 10a). This highlights that the basinintegrated transformation is critically dependent on the processes regulating the intensity of near-boundary mixing and those governing the structure of near-boundary stratification. In the Orkney Deep, the key near-boundary mixingand stratification-controlling processes have been shown to be intrinsically related to the DWBC, via interaction with the sloping boundary, driving a downslope bottom Ekman flow (Naveira Garabato et al. 2019). This flow advects relatively light water downslope, tilting isoneutrals toward vertical, reducing stratification and promoting turbulent mixing via convection. The bottom Ekman flow also results in horizontal compression of isoneutrals, and enhancement of lateral shears, thereby generating conditions favorable for development of submesoscale symmetric and centrifugal instabilities (Wenegrat et al. 2018; Naveira Garabato et al. 2019). These instabilities drive further turbulent mixing, lateral exchange 
of near-boundary and off-boundary waters, and a restratification of the boundary (Fig. 10b), which may subsequently continue via baroclinic instability (Callies 2018; Wenegrat et al. 2018). Thus, all available evidence suggests that the intense, dianeutrally convergent water-mass transformation occurring in the Orkney Deep is closely tied to the DWBC.

A further notable feature of the turbulent mixing in the Orkney Deep is its remarkably high dissipation ratio $(\Gamma=0.6-$ 1.1), which substantially exceeds the value of 0.2 expected for stratified shear turbulence (Gregg et al. 2018). This elevated dissipation ratio enables the turbulence in the DWBC to drive a considerably stronger mixing and transformation (by a factor of 3-6) than if it operated with the dissipation ratio typical of most of the ocean. Although our data do not definitively constrain the factors behind this result, it is possible that the highly efficient mixing in the basin is related to the weak near-boundary stratification generated at the DWBC's base by the downslope bottom Ekman flow.

The findings reported in this paper have several significant implications for our understanding of the overturning circulation of the deep ocean. First, our results provide observational evidence endorsing a paradigm of deep-ocean overturning driven by near-boundary mixing (Huussen et al. 2012; de Lavergne et al. 2016b; Ferrari et al. 2016; McDougall and Ferrari 2017; Cimoli et al. 2019; Drake et al. 2020). In this view, the upwelling branch of deep-ocean overturning is primarily effected by near-boundary mixing, whereas mixing away from boundaries acts to induce dianeutral downwelling - just as documented here for the Orkney Deep. Second, our work expands this paradigm by highlighting the potential role of DWBCs in hosting a substantial fraction of the deep-ocean upwelling on basin scales. To provide a very rough illustration, if dianeutral upwelling at the rate diagnosed for some density classes in the Orkney Deep (0.4 Sv over $200 \mathrm{~km}$ of DWBC) occurred along the entire meridional length (on the order of $5000-10000 \mathrm{~km}$ ) of the Atlantic, Indian, or Pacific basins (a clear oversimplification, since the upwelling is likely to apply to different density classes in different regions), it could sustain upwelling on the order of 10-20 Sv, which is comparable to the net basin-integrated upwelling (Ganachaud and Wunsch 2000; Lumpkin and Speer 2007; Talley 2013). Thus, despite the crude nature of the previous scaling, the possibility that DWBCs may be important hotspots of dianeutral upwelling deserves further investigation.

Finally, the inferred physical coupling between turbulent mixing and the DWBC's flow over sloping topography suggests that the mixing, and the water-mass transformation it controls, must be responsive to changes in the intensity of the DWBC and in the external forcings of such changes. Indirect evidence of this sensitivity in the Orkney Passage complex is provided by past investigations of the climatic variability in the properties of AABW in the Scotia Sea, immediately downstream of the Orkney Deep (Jullion et al. 2010; Meredith et al. 2011). These reveal that $\mathrm{AABW}$ in the region warms (cools) in response to an intensification (weakening) of zonal winds over the northern Weddell Sea with a short lag of a few months, consistent with barotropic acceleration (deceleration) of the DWBC leading to a bottom Ekman-induced increase (decrease) in the intensity of turbulent mixing (Meredith et al. 2011). If this mechanism is widely relevant to other DWBC systems, our findings suggest that deep-ocean water-mass transformation and overturning may be more variable and climatically reactive than currently thought.

Acknowledgments. CS, ACNG, AF, and EFW were supported by the U.K. Natural Environment Research Council (NERC) Grant NE/K013181/1. ACNG was supported by the Royal Society and Wolfson Foundation. EPA and CEB were supported by NERC Grant NE/K012843/1. CEB was funded by an MSCA grant (No. 798319) from the European Union's Horizon 2020 program. EPA was supported by NERC Grant NE/N018095/1. SL and KP were supported by U.S. National Science Foundation Grants OCE-1536453 and OCE-1536779. SL acknowledges support of Award NA18OAR4320123 from the National Oceanic and Atmospheric Administration, U.S. Department of Commerce. The statements, findings, conclusions, and recommendations are those of the authors, and do not necessarily reflect the views of the National Oceanic and Atmospheric Administration, or the U.S. Department of Commerce. We thank the scientists, crew, and technicians of the RRS James Clark Ross for their hard work.

Data availability statement. The observational datasets used in this paper are available from the British Oceanographic Data Centre (BODC). The numerical model code and data are available at https://doi.org/10.5281/zenodo.4313829.

\section{REFERENCES}

Abrahamsen, E. P., 2019: A bathymetric compilation around the South Orkney Islands, 1987-2017 (version 1.0). UK Polar Data Centre, Natural Environment Research Council, UK Research \& Innovation, accessed 22 July 2019, https:// doi.org/10.5285/1158843c-d238-439a-ad42-9645f37ac582.

, and Coauthors, 2019: Stabilization of dense Antarctic water supply to the Atlantic Ocean overturning circulation. Nat. Climate Change, 9, 742-746, https://doi.org/10.1038/ s41558-019-0561-2.

Bogucki, D. J., H. Luo, and J. A. Domaradzki, 2012: Experimental evidence of the Kraichnan scalar spectrum at high Reynolds numbers. J. Phys. Oceanogr., 42, 1717-1728, https://doi.org/ 10.1175/JPO-D-11-0214.1.

Brink, K. H., and S. Lentz, 2010: Buoyancy arrest and bottom Ekman transport. Part I: Steady flow. J. Phys. Oceanogr., 40, 621-635, https://doi.org/10.1175/2009JPO4266.1.

Callies, J., 2018: Restratification of abyssal mixing layers by submesoscale baroclinic eddies. J. Phys. Oceanogr., 48, 1995-2010, https://doi.org/10.1175/JPO-D-18-0082.1.

Cimoli, L., C.-C. P. Caulfield, H. L. Johnson, D. P. Marshall, A. Mashayek, A. C. Naveira Garabato, and C. Vic, 2019: Sensitivity of deep ocean mixing to local tide breaking and mixing efficiency. Geophys. Res. Lett., 46, 14 622-14 633, https:// doi.org/10.1029/2019GL085056.

Davies Wykes, M., and S. Dalziel, 2014: Efficient mixing in stratified flows: Experimental study of a Rayleigh-Taylor unstable interface within an otherwise stable stratification. J. Fluid Mech., 756, 1027-1057, https://doi.org/10.1017/jfm.2014.308.

de Lavergne, C., G. Madec, J. Le Sommer, A. G. Nurser, and A. C. Naveira Garabato, 2016a: The impact of a variable 
mixing efficiency on the abyssal overturning. J. Phys. Oceanogr., 46, 663-681, https://doi.org/10.1175/JPO-D-14-0259.1.

,,,--- , and A. C. N. Garabato, 2016b: On the consumption of Antarctic Bottom Water in the abyssal ocean. J. Phys. Oceanogr., 46, 635-661, https://doi.org/10.1175/JPO-D14-0201.1.

Desbruyères, D. G., S. G. Purkey, E. L. McDonagh, G. C. Johnson, and B. A. King, 2016: Deep and abyssal ocean warming from 35 years of repeat hydrography. Geophys. Res. Lett., 43, 10356-10365, https://doi.org/10.1002/2016GL070413.

Drake, H. F., R. Ferrari, and J. Callies, 2020: Abyssal circulation driven by near-boundary mixing: Water mass transformations and interior stratification. J. Phys. Oceanogr., 50, 2203-2226, https://doi.org/10.1175/JPO-D-19-0313.1.

Ferrari, R., M. F. Jansen, J. F. Adkins, A. Burke, A. L. Stewart, and A. F. Thompson, 2014: Antarctic sea ice control on ocean circulation in present and glacial climates. Proc. Natl. Acad. Sci. USA, 111, 8753-8758, https://doi.org/10.1073/pnas.1323922111.

__- A. Mashayek, T. J. McDougall, M. Nikurashin, and J.-M. Campin, 2016: Turning ocean mixing upside down. J. Phys. Oceanogr., 46, 2239-2261, https://doi.org/10.1175/JPO-D15-0244.1.

Furlong, M. E., D. Paxton, P. Stevenson, M. Pebody, S. D. McPhail, and J. Perrett, 2012: Autosub long range: A long range deep diving AUV for ocean monitoring. IEEE/OES Autonomous Underwater Vehicles ( $A U V$ ), Southampton, United Kingdom, IEEE, 1-7, https://doi.org/10.1109/AUV.2012.6380737.

Ganachaud, A., and C. Wunsch, 2000: Improved estimates of global ocean circulation, heat transport and mixing from hydrographic data. Nature, 408, 453-457, https://doi.org/10.1038/35044048.

Gayen, B., G. O. Hughes, and R. W. Griffiths, 2013: Completing the mechanical energy pathways in a turbulent RayleighBenard convection. Phys. Rev. Lett., 111, 124301, https:// doi.org/10.1103/PhysRevLett.111.124301.

Gordon, A. L., M. Visbeck, and B. Huber, 2001: Export of Weddel Sea deep and bottom water. J. Geophys. Res., 106, 9005-9017, https://doi.org/10.1029/2000JC000281.

Goutorbe, B., J. Poort, F. Lucazeau, and S. Raillard, 2011: Global heat flow trends resolved from multiple geological and geophysical proxies. Geophys. J. Int., 187, 1405-1419, https:// doi.org/10.1111/j.1365-246X.2011.05228.x.

Gregg, M., E. D'Asaro, and E. Kunze, 2018: Mixing efficiency in the ocean. Annu. Rev. Mar. Sci., 10, 443-473, https://doi.org/ 10.1146/annurev-marine-121916-063643.

Groeskamp, S., S. M. Griffies, D. Iudicone, R. Marsh, A. G. Nurser, and J. D. Zika, 2019: The water mass transformation framework for ocean physics and biogeochemistry. Annu. Rev. Mar. Sci., 11, 271-305, https://doi.org/10.1146/ annurev-marine-010318-095421.

Heywood, K. J., A. C. Naveira Garabato, and D. P. Stevens, 2002: High mixing rates in the abyssal Southern Ocean. Nature, 415, 1011-1014, https://doi.org/10.1038/4151011a.

Huussen, T. N., A. C. Naveira Garabato, H. L. Bryden, and E. L. McDonagh, 2012: Is the deep Indian Ocean MOC sustained by breaking internal waves? J. Geophys. Res., 117, C08024, https://doi.org/10.1029/2012JC008236.

Iudicone, D., G. Madec, and T. J. McDougall, 2008: Water-mass transformations in a neutral density framework and the key role of light penetration. J. Phys. Oceanogr., 38, 1357-1376, https://doi.org/10.1175/2007JPO3464.1.

Jackett, D. R., and T. J. McDougall, 1997: A neutral density variable for the world's oceans. J. Phys. Oceanogr., 27, 237-263, https:// doi.org/10.1175/1520-0485(1997)027<0237:ANDVFT>2.0.CO;2.
Jullion, L., S. C. Jones, A. C. Naveira Garabato, and M. P. Meredith, 2010: Wind-controlled export of Antarctic Bottom Water from the Weddell Sea. Geophys. Res. Lett., 37, L09609, https://doi.org/10.1029/2010GL042822.

Kaminski, A. K., and W. D. Smyth, 2019: Stratified shear instability in a field of pre-existing turbulence. J. Fluid Mech., 862, 639-658, https://doi.org/10.1017/jfm.2018.973.

Kawase, M., 1987: Establishment of deep ocean circulation driven by deep-water production. J. Phys. Oceanogr., 17, 2294-2317, https:// doi.org/10.1175/1520-0485(1987)017<2294:EODOCD>2.0.CO;2.

Klocker, A., and T. J. McDougall, 2010: Influence of the nonlinear equation of state on global estimates of dianeutral advection and diffusion. J. Phys. Oceanogr., 40, 1690-1709, https:// doi.org/10.1175/2010JPO4303.1.

Kunze, E., 2017: The internal-wave-driven meridional overturning circulation. J. Phys. Oceanogr., 47, 2673-2689, https://doi.org/ 10.1175/JPO-D-16-0142.1.

Lumpkin, R., and K. Speer, 2007: Global ocean meridional overturning. J. Phys. Oceanogr., 37, 2550-2562, https://doi.org/ 10.1175/JPO3130.1.

Marshall, J., A. Adcroft, C. Hill, L. Perelman, and C. Heisey, 1997: A finite-volume, incompressible Navier Stokes model for studies of the ocean on parallel computers. J. Geophys. Res., 102, 5753-5766, https://doi.org/10.1029/96JC02775.

Mashayek, A., and W. R. Peltier, 2013: Shear-induced mixing in geophysical floes: Does the route to turbulence matter to its efficiency? J. Fluid Mech., 725, 216-261, https://doi.org/10.1017/ jfm.2013.176.

_ - H. Salehipour, D. Bouffard, C. Caulfield, R. Ferrari, M. Nikurashin, W. Peltier, and W. Smyth, 2017: Efficiency of turbulent mixing in the abyssal ocean circulation. Geophys. Res. Lett., 44, 6296-6306, https://doi.org/10.1002/ 2016GL072452.

McDougall, T., 1984: The relative roles of diapycnal and isopycnal mixing on subsurface water mass conversion. J. Phys. Oceanogr., 14, 1577-1589, https://doi.org/10.1175/1520-0485(1984)014<1577: TRRODA $>2.0 . \mathrm{CO} ; 2$.

—_, and R. Ferrari, 2017: Abyssal upwelling and downwelling driven by near-boundary mixing. J. Phys. Oceanogr., 47, 261-283, https:// doi.org/10.1175/JPO-D-16-0082.1.

Melet, A., R. Hallbery, S. Legg, and K. Polzin, 2013: Sensitivity of the ocean state to the vertical distribution of internal-tidedriven mixing. J. Phys. Oceanogr., 43, 602-615, https://doi.org/ 10.1175/JPO-D-12-055.1.

Meredith, M. P., A. L. Gordon, A. C. Naveira Garabato, E. P. Abrahamsen, B. A. Huber, L. Jullion, and H. J. Venables, 2011: Synchronous intensification and warming of Antarctic Bottom Water outflow from the Weddell Gyre. Geophys. Res. Lett., 38, L03603, https://doi.org/10.1029/2010GL046265.

Munk, W. H., 1966: Abyssal recipes. Deep-Sea Res. Oceanogr. Abstr., 13, 707-730, https://doi.org/10.1016/0011-7471(66) 90602-4.

Naveira Garabato, A. C., 2017: Cruise report RRS James Clark Ross cruise JR16005: The dynamics of the Orkney Passage outflow (DynOPO). National Oceanography Centre, 222 pp., https:// www.bodc.ac.uk/resources/inventories/cruise_inventory/reports/ jr16005.pdf.

, E. L. McDonagh, D. P. Stevens, K. J. Heywood, and R. J. Sanders, 2002: On the export of Antarctic Bottom Water from the Weddell Sea. Deep-Sea Res. II, 49, 4715-4742, https:// doi.org/10.1016/S0967-0645(02)00156-X.

_ A. P. Williams, and S. Bacon, 2014: The three-dimensional overturning circulation of the Southern Ocean during the 
WOCE era. Prog. Oceanogr., 120, 41-78, https://doi.org/10.1016/ j.pocean.2013.07.018.

__ , and Coauthors, 2019: Rapid mixing and exchange of deepocean waters in an abyssal boundary current. Proc. Natl. Acad. Sci. USA, 116, 13 233-13 238, https://doi.org/10.1073/ pnas.1904087116.

Nikurashin, M., and G. Vallis, 2011: A theory of deep stratification and overturning circulation in the ocean. J. Phys. Oceanogr., 41, 485-502, https://doi.org/10.1175/2010JPO4529.1.

—- and - 2012: A theory of the interhemispheric meridional overturning circulation and associated stratification. J. Phys. Oceanogr., 42, 1652-1667, https://doi.org/10.1175/ JPO-D-11-0189.1.

Nurser, A. J. G., R. Marsh, and R. G. Williams, 1999: Diagnosing water mass formation from air-sea fluxes and surface mixing. J. Phys. Oceanogr., 29, 1468-1487, https://doi.org/10.1175/ 1520-0485(1999)029<1468:DWMFFA>2.0.CO;2.

Oakey, N. S., 1982: Determination of the rate of dissipation of turbulent energy from simultaneous temperature and velocity shear microstructure measurements. J. Phys. Oceanogr., 12, 256-271, https://doi.org/10.1175/1520-0485(1982)012<0256: DOTROD $>2.0$.CO;2.

Osborn, T. R., 1980: Estimates of the local rate of vertical diffusion from dissipation measurements. J. Phys. Oceanogr., 10, 83-89, https://doi.org/10.1175/1520-0485(1980)010<0083: EOTLRO $>2.0 . \mathrm{CO} ; 2$.

Patara, L., and C. W. Boning, 2014: Abyssal ocean warming around Antarctica strengthens the Atlantic overturning circulation. Geophys. Res. Lett., 41, 3972-3978, https://doi.org/10.1002/ 2014GL059923.

Polzin, K., A. C. Naveira Garabato, E. P. Abrahamsen, L. Jullion, and M. P. Meredith, 2014: Boundary mixing in Orkney Passage outflow. J. Geophys. Res. Oceans, 119, 8627-8645, https://doi.org/10.1002/2014JC010099.

Polzin, K. L., J. M. Toole, J. R. Ledwell, and R. W. Schmitt, 1997: Spatial variability of turbulent mixing in the abyssal ocean. Science, 276, 93-96, https://doi.org/10.1126/science.276.5309.93.

Prather, M. J., 1986: Numerical advection by conservation of second-order moments. J. Geophys. Res., 91, 6671-6681, https://doi.org/10.1029/JD091iD06p06671.

Purkey, S. G., and G. C. Johnson, 2013: Antarctic Bottom Water warming and freshening: Contributions to sea level rise, ocean freshwater budgets, and global heat gain. J. Climate, 26, 6105-6122, https://doi.org/10.1175/JCLI-D-12-00834.1.

Salehipour, H., W. R. Peltier, and A. Mashayek, 2015: Turbulent diapycnal mixing in stratified shear flows: The influence of
Prandtl number on mixing efficiency and transition at high Reynolds number. J. Fluid Mech., 773, 178-223, https:// doi.org/10.1017/jfm.2015.225.

Smyth, W., J. Moum, and D. Caldwell, 2001: The efficiency of mixing in turbulent patches: Inferences from direct simulations and microstructure observations. J. Phys. Oceanogr., 31, 1969-1992, https://doi.org/10.1175/1520-0485(2001)031<1969: TEOMIT $>2.0$. CO; 2 .

St. Laurent, L. C. S., J. M. Toole, and R. W. Schmitt, 2001: Buoyancy forcing by turbulence above rough topography in the abyssal Brazil basin. J. Phys. Oceanogr., 31, 3476-3495, https://doi.org/ 10.1175/1520-0485(2001)031<3476:BFBTAR>2.0.CO;2.

Stöber, U., M. Walter, C. Mertens, and M. Rhein, 2008: Mixing estimates from hydrographic measurements in the deep western boundary current of the North Atlantic. Deep-Sea Res. I, 55, 721-736, https://doi.org/10.1016/j.dsr.2008.03.006.

Stommel, H., and A. B. Arons, 1960: On the abyssal circulation of the world ocean - II. An idealised model of the circulation pattern and amplitude in oceanic basins. Deep-Sea Res., 6, 217-233, https://doi.org/10.1016/0146-6313(59)90075-9.

Talley, L. D., 2013: Closure of the global overturning circulation through the Indian, Pacific and Southern Oceans: Schematics and transports. Oceanography, 26, 80-97, https://doi.org/10.5670/ oceanog.2013.07.

Thompson, L., and G. C. Johnson, 1996: Abyssal currents generated by diffusion and geothermal heating over rises. DeepSea Res. I, 43, 193-211, https://doi.org/10.1016/0967-0637(96) 00095-7.

Visbeck, M., 2002: Deep velocity profiling using lowered acoustic Doppler current profilers: Bottom track and inverse solutions. J. Atmos. Oceanic Technol., 19, 794-807, https://doi.org/ 10.1175/1520-0426(2002)019<0794:DVPULA > 2.0.CO;2.

Walin, G., 1982: On the relation between sea-surface heat flow and thermal circulation in the ocean. Tellus, 34, 187-195, https:// doi.org/10.3402/tellusa.v34i2.10801.

Waterhouse, A. F., and Coauthors, 2014: Global patterns of diapycnal mixing from measurements of the turbulent dissipation rate. J. Phys. Oceanogr., 44, 1854-1872, https://doi.org/10.1175/ JPO-D-13-0104.1.

Watson, A. J., and A. C. Naveira Garabato, 2006: The role of southern ocean mixing and upwelling in the glacial-interglacial atmospheric $\mathrm{CO}_{2}$ change. Tellus, 58B, 73-87, https://oi.org/ 10.1111/j.1600-0889.2005.00167.x.

Wenegrat, J. O., J. Callies, and L. N. Thomas, 2018: Submesoscale baroclinic instability in the bottom boundary layer. J. Phys. Oceanogr., 48, 2571-2592, https://doi.org/10.1175/JPO-D-17-0264.1. 